\title{
Simulated Impact of the Tibetan Glacier Expansion on the Eurasian Climate and Glacial Surface Mass Balance during the Last Glacial Maximum ${ }^{\mathscr{O}}$
}

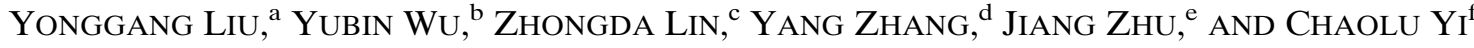 \\ ${ }^{a}$ Department of Atmospheric and Oceanic Sciences, Peking University, Beijing, China \\ ${ }^{\mathrm{b}}$ State Key Laboratory of Loess and Quaternary Geology, Institute of Earth Environment, \\ Chinese Academy of Sciences, Beijing, China \\ ${ }^{\mathrm{c}}$ State Key Laboratory of Numerical Modeling for Atmospheric Sciences and Geophysical Fluid Dynamics, \\ Institute of Atmospheric Physics, Chinese Academy of Sciences, Beijing, China \\ ${ }^{\mathrm{d}}$ School of Atmospheric Sciences, Nanjing University, Nanjing, China \\ ${ }^{\mathrm{e}}$ Department of Earth and Environmental Sciences, University of Michigan, Ann Arbor, Michigan \\ ${ }^{\mathrm{f}}$ Institute of Tibetan Plateau Research, Center for Excellence in Tibetan Plateau Earth Sciences, \\ Chinese Academy of Sciences, Beijing, China
}

(Manuscript received 11 October 2019, in final form 25 March 2020)

\begin{abstract}
Glaciers over the Tibetan Plateau and surrounding regions during the Last Glacial Maximum (LGM) were much more extensive than during the preindustrial period (PI). The climate impact of such glacial expansion is studied here using the Community Atmosphere Model, version 4 (CAM4). To cover the range of uncertainty in glacier area during the LGM, the following three values are tested: $0.35 \times 10^{6}, 0.53 \times 10^{6}$, and $0.70 \times 10^{6} \mathrm{~km}^{2}$. The added glacier is distributed approximately equally over the Pamir region and the Himalayas. If $0.70 \times 10^{6} \mathrm{~km}^{2}$ is used, the annual mean surface temperature of the glaciated regions would be cooled by $\sim 3.5^{\circ} \mathrm{C}$. The annual mean precipitation would be reduced by $0.2 \mathrm{~mm} \mathrm{day}{ }^{-1}(10 \%)$ and $2.5 \mathrm{~mm} \mathrm{day}^{-1}(24 \%)$ over the Pamir region and Himalayas, respectively. The surface mass balance (SMB) of the glaciers changes by $0.55 \mathrm{~m} \mathrm{yr}^{-1}(280 \%)$ and $-0.32 \mathrm{~m} \mathrm{yr}^{-1}(-20 \%)$ over the two regions, respectively. The changes in SMB remain large $\left(0.29\right.$ and $\left.-0.13 \mathrm{~m} \mathrm{yr}^{-1}\right)$, even if the area of the Tibetan glacier were $0.35 \times 10^{6} \mathrm{~km}^{2}$. Therefore, based on the results of this particular model, the expansion of glaciers can either enhance or slow the glacial growth. Moreover, the expansion of glaciers over the Himalayas reduces summer precipitation in central and northern China by $\sim 0.5 \mathrm{~mm}_{\text {day }}{ }^{-1}$ and increases summer precipitation in southern Asia by $\sim 0.6 \mathrm{~mm} \mathrm{day}^{-1}$. The expansion of glaciers over the Pamir region has a negligible influence on the precipitation in these monsoonal regions, which is likely due to its large distance from the main monsoonal regions.
\end{abstract}

\section{Introduction}

The extent of glaciers on the Tibetan Plateau and surrounding area during the Last Glacial Maximum (LGM; 28-23 ka) (Hughes and Gibbard 2015) was much greater than that of the present day, but the exact value is hard to estimate due to difficulties in identifying and dating the moraines in all regions (Owen and Dortch 2014; see their Fig. 5 for a summary of reconstructions by different researchers). The reconstruction by $\mathrm{Li}$ and $\mathrm{Li}$ (1991) provided a

Supplemental information related to this paper is available at the Journals Online website: https://doi.org/10.1175/JCLI-D-19-0763.s1.

Corresponding author: Chaolu Yi, clyi@itpcas.ac.cn glacial area estimate of approximately $0.35 \times 10^{6} \mathrm{~km}^{2}$ excluding the part on the Pamir Plateau (see Fig. S1 in the online supplemental material). Kuhle (1985, 1998, 2005) argued that there was even a Tibetan ice sheet that existed during the LGM with an area over $2 \times 10^{6} \mathrm{~km}^{2}$. However, this view was challenged by later observational studies (e.g., Heyman 2014; Owen and Dortch 2014; Shi et al. 1992). Climate simulations, especially those with relatively high spatial resolutions (finer than $2^{\circ} \times 2^{\circ}$ ), showed that the decrease in equilibriumline altitude (ELA) ${ }^{1}$ during the LGM relative to the

\footnotetext{
${ }^{1}$ ELA marks the area or zone on a glacier separating the accumulation zone from the ablation zone and represents where annual accumulation and ablation are equal (Bakke and Nesje 2011).
} 
preindustrial period (PI) would allow for a more extensive accumulation of snow in only the marginal regions of the plateau (Jiang et al. 2019), which is consistent with the reconstructions (Heyman 2014; Shi et al. 1997). The direct simulation of the glacial expansion during the LGM gave a best estimate of $0.81 \times 10^{6} \mathrm{~km}^{2}$ (2018), which is much larger than that of the present day of approximately $0.08 \times 10^{6} \mathrm{~km}^{2}$ (Arendt et al. 2015; Nuimura et al. 2015). To the best of our knowledge, how such a change in glacial area over the Tibetan Plateau impacts regional and remote climate conditions has not been studied in detail.

The climate impact of glacial expansion over the Tibetan region is twofold: 1) Glacial expansion impacts the local temperature and precipitation (He 2011), which then acts as feedback to the glacial area by changing the glacier surface mass balance. Without knowing its importance, this feedback was generally neglected in previous studies simulating glacial changes over the Tibetan Plateau during the LGM. For example, Yan et al. (2018) used a glacier model to simulate the glacial extent over the Tibetan region during the LGM. The model was driven with the temperature and precipitation provided by phases II and III of the Paleoclimate Modelling Intercomparison Project (PMIP2 and 3; https:// pmip.lsce.ipsl.fr). However, both PMIP2 and PMIP3 simulated the LGM climate by assuming that the glacial extent was the same as that of the present day (Schmidt et al. 2012). A similar practice has also been exercised by other researchers but with ice sheet models with much coarser spatial resolutions (e.g., Kirchner et al. 2009, 2011). 2) The Tibetan Plateau acts as a heating source of the middle to upper atmosphere during the summer and is important for the Asian summer monsoons (ASM; e.g., Hahn and Manabe 1975; Li and Yanai 1996; Wu et al. 2007; Ye and Wu 1998). It has recently been debated whether it is the topographic blocking effect or the heating effect of the plateau that is more important for the South Asian summer monsoon (SASM) (Boos and Kuang 2010, 2013; Ma et al. 2014; Wu et al. 2016, 2015). The importance of the plateau heating to the East Asian summer monsoon (EASM; e.g., Liu and Yin 2002) seems to be more robust (Lu et al. 2018), although it has also very recently been challenged by a modeling study using idealized continents (Son et al. 2019). An expansion of glaciers is therefore expected to reduce the heating of the atmosphere and impact the ASM. Neither of these impacts has been quantitatively investigated before.

Jiang et al. $(2002,2003)$ studied the glacial expansion influence over the Tibetan Plateau during the LGM on the climate over mainly East Asia and found that it significantly weakened EASM. However, their studies assumed that the whole or majority of the Tibetan
Plateau was covered by an ice sheet. Jin et al. (2009, 2006, 2005) studied the influence of some idealized glacial changes over the Tibetan Plateau during the Holocene and found that the expansion of glaciers greatly weakened the SASM. Many experiments have been performed in which the surface heat flux over different regions on or around the Tibetan Plateau was suppressed (e.g., Boos and Kuang 2010, 2013; Duan et al. 2017; Liu et al. 2017b; Ma et al. 2014; Wu et al. 2016, 2015). These studies mimicked the effect of glacial expansion, but all were done in an idealized manner (the area of the glaciers was generally comparable to the size of the Tibetan Plateau) and in the context of the presentday climate.

The anomalous snow coverage influence on the climate of the surrounding and remote regions of the Tibetan Plateau through teleconnection has been investigated by various researchers (Lin and $\mathrm{Wu} 2011$, 2012; Liu et al. 2014, 2017a). Although anomalously large snow cover has similar climate impact to the expansion of glaciers, it does not last longer than a few months; the influence of this snow cover is only important for the interannual climate variability.

In this study, we investigate the influence of glacial expansion over the Tibetan Plateau on the LGM climate in a more realistic way; the glacier expanded over only the mountains riming the Tibetan Plateau rather than over the whole plateau as was completed in previous studies (e.g., by changing surface albedo or heat fluxes; Boos and Kuang 2010; Duan et al. 2017). In particular, we are interested in how glacial expansion impacts the local temperature and precipitation over the glaciers and the ASM. In addition, the influence of glacial expansion over the western part (including the Pamir Plateau and Karakorum Mountains; Fig. 1a) and the Himalayas (Fig. 1b) is also separately investigated. The former is herein referred to as the Pamir region for the sake of simplicity, and the Pamir Plateau is meant to be included when the Tibetan Plateau is mentioned throughout the paper for the same reason.

As will be demonstrated in the following sections, the glacial expansion impacts the local temperature and precipitation, which then have significant influences on the surface mass balances of the glaciers themselves. Interestingly, the signs of changes in the surface mass balance are different between the Pamir region and the Himalayas. Moreover, the glacial expansion over the Himalayas has a much larger influence on the ASM than that over the Pamir region.

In addition, it will be briefly demonstrated that the impact of the same glacial expansion on the ASM would be significantly smaller for the PI than for the LGM; thus, studies conducted in the context of PI may not be 

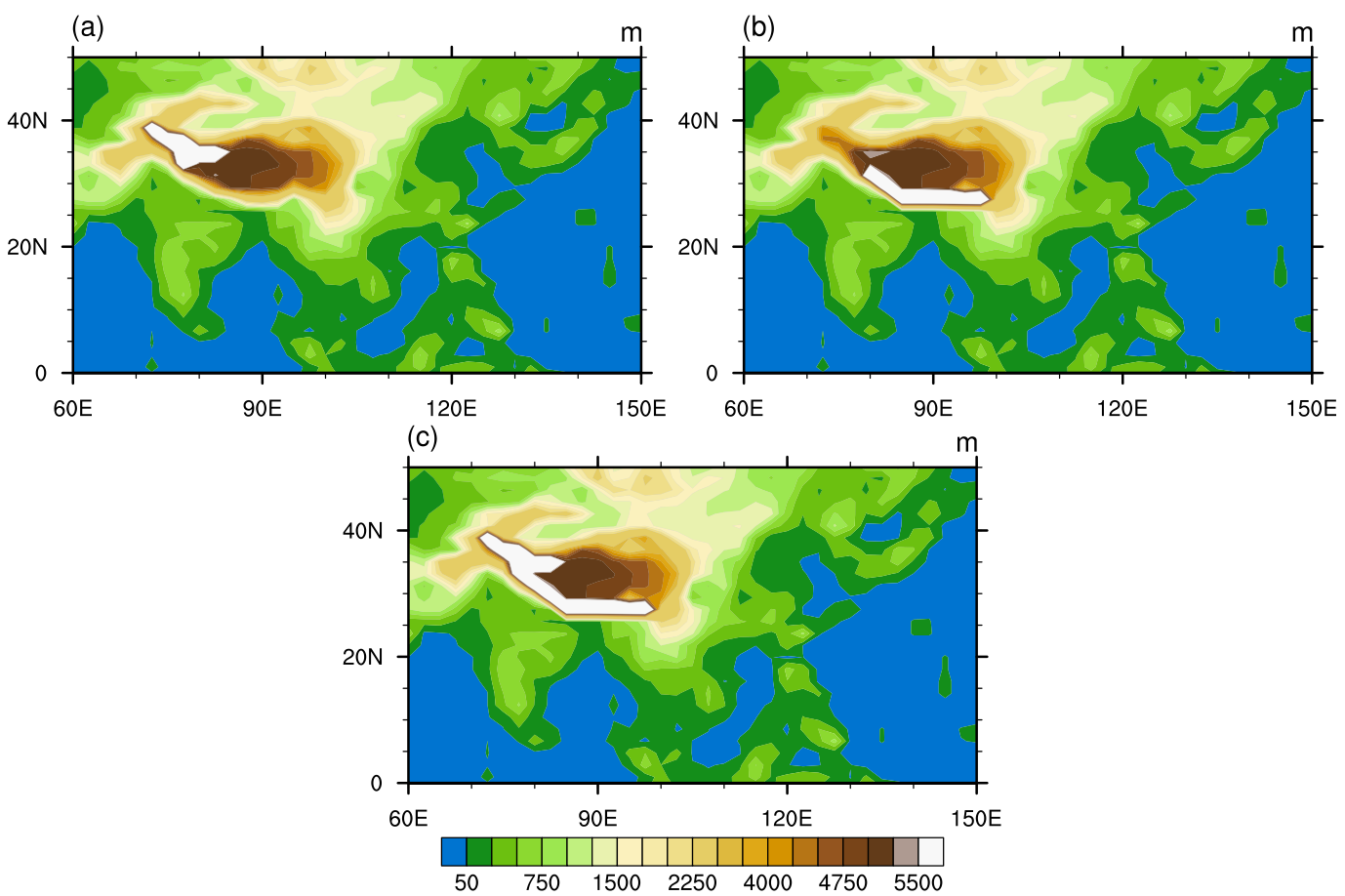

FIG. 1. Elevation map showing the regions where glacial area (white color) is increased in the (a) Pamir experiment, (b) Himalayan experiment, and (c) the Tibet experiment. The increase in glacial area is achieved by increasing the glacial fraction (may not be $100 \%$ ) in each grid cell of the model.

used to infer the impact during the LGM. Some preliminary results of this investigation have been published in Wu et al. (2019), where the sea surface temperatures (SSTs) used were from unequilibrated Community Earth System Model, version 1.2 (CESM1.2), runs for both the LGM and the PI. Thus, the results were quantitatively different from those of the current study. Moreover, the impact of glacial expansion on the surface mass balance of glaciers was not analyzed, nor were there any mechanism analyses. Furthermore, the separate influence of glacial expansion over different parts of the Tibetan Plateau was not investigated.

The rest of the paper is organized as follows: In section 2, the model configuration and experimental setup are described. In section 3, the results for glacial expansion over different sectors of the Tibetan Plateau are presented. In section 4 , the mechanisms of the climate impact of glacial expansion are briefly discussed. Finally, the major conclusions are presented in section 5 .

\section{Model configuration and experimental setup}

\section{a. CESM1.2 and climate simulations}

In this study, we employ the Community Atmosphere Model, version 4 (CAM4), coupled with the Community
Land Model, version 4 (CLM4), within the framework of CESM1.2 (Hurrell et al. 2013). CESM1.2, which is maintained by the National Center for Atmospheric Research (NCAR) of the United States, is a state-ofthe-art Earth system model that produces better simulations of the Asian monsoons than most of the other models that have participated in phase 5 of the Coupled Model Intercomparison Project (CMIP5) (Anand et al. 2018; Jiang et al. 2016; Sperber et al. 2013) and has been used to study the changes in Asian monsoons due to aerosols, greenhouse gases, and surface albedo (e.g., Boos and Storelvmo 2016; Vinoj et al. 2014).

The finite-volume dynamic core is used for the CAM4, with a nominal $2^{\circ}$ horizontal resolution, that is, $1.9^{\circ}$ (latitude) $\times 2.5^{\circ}$ (longitude). The atmosphere is divided into 26 layers in the vertical direction, and the top of the model is at $3 \mathrm{hPa}$. CLM4 has the same horizontal resolution as the CAM4. The time step for both components is $1800 \mathrm{~s}$. For the LGM, the orbital configuration is that of $21 \mathrm{ka}$, and the greenhouse gas concentrations and ice sheet topography are all the same as those in the LGM experiments designed by PMIP3 (Schmidt et al. 2012). For PI, the atmospheric concentrations of $\mathrm{CO}_{2}, \mathrm{CH}_{4}$, and $\mathrm{N}_{2} \mathrm{O}$ are 284.7 ppmv, $791.6 \mathrm{ppbv}$, and $275.7 \mathrm{ppbv}$, respectively. SST is prescribed in both the LGM and PI experiments. The LGM SST is from the equilibrated 
simulation in Zhu et al. (2017), and the PI SST is from the equilibrium state of the B1850 component set of CESM1.2.

Six experiments were carried out for the LGM, one is the control run (CTRL) with the default (present day) Tibetan glacier, and the other five experiments are the perturbation runs with changed glaciers (summarized in Table 1). In the first three perturbation runs, the glacial areas are increased over both the Pamir region and the Himalayas (Fig. 1c), with total glacier areas being $\sim 0.35 \times 10^{6} \mathrm{~km}^{2}$ (experiment LGM_T35), $0.53 \times 10^{6} \mathrm{~km}^{2}$ (LGM_T53), and $0.70 \times 10^{6} \mathrm{~km}^{2}$ (LGM_T70), respectively. Individual glaciers are on the kilometer scale, which is much smaller than the length scale of the model grid boxes $(\sim 200 \mathrm{~km})$; only the areal fraction of all glaciers within each grid box needs to be provided to the model. In these three runs, the glacial fraction in 15 grid boxes is modified (white areas in Fig. 1c). The glacial fraction is set to be approximately $33 \%, 66 \%$, and $99 \%$ in each grid box for the first three perturbation runs, respectively.

Three different glacial areas are tested to cover the uncertainty range in the reconstructions and model simulations. The minimum value should be $\sim 0.35 \times 10^{6} \mathrm{~km}^{2}$ according to the reconstruction by $\mathrm{Li}$ and $\mathrm{Li}$ (1991) and at least as large as $\sim 0.70 \times 10^{6} \mathrm{~km}^{2}$ according to the simulations by Yan et al. (2018). Note that the simulated glacial expansion in Yan et al. (2018) also includes the expansion over Tian Shan Mountain, but the area change there is very small (see their Fig. 5a), and therefore, the change is neglected here.

In the fourth and fifth perturbation runs, the glacier is increased over only the Pamir (Fig. 1a) and the Himalayas (Fig. 1b), respectively, with the glacial area being $\sim 0.35 \times 10^{6} \mathrm{~km}^{2}$ for both experiments (LGM_P35 and LGM_H35). The setup of these two experiments was motivated by the results of experiment LGM_T70, in which the precipitation and the seasonal cycle of the surface temperature respond quite differently to glacial expansion. Then, the glaciated region of LGM_T70 (Fig. 1c) is divided into two regions, which happen to have similar areas. Division of the region into more parts did not seem to be warranted. The responses of precipitation in Asia to glacial expansion over the Pamir region and Himalayas were very different.

The influence of the thickness change of glaciers is neglected in the current study due to the following consideration. The glacier thickness of the present day is generally smaller than $300 \mathrm{~m}$ and occasionally reaches $500 \mathrm{~m}$ (e.g., Gärtner-Roer et al. 2014). The glacier thickness during the LGM was probably larger. The mean thickness of Tibetan glaciers in a single modeling study was $\sim 380 \mathrm{~m}$ (Yan et al. 2018), but the

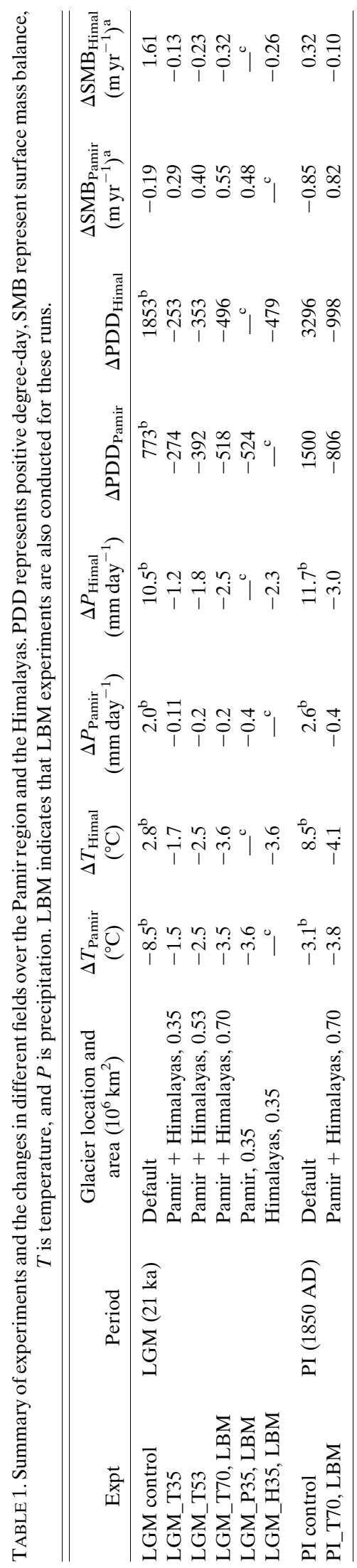


thickness of a few individual valley glaciers constrained by both modeling and reconstruction was only 42-132 m (e.g., Xu and Glasser 2015; Xu and Yi 2017; $\mathrm{Xu}$ et al. 2017). Such thickness change is quite small compared to the elevation of unresolved Tibetan mountains under the current model resolution.

For the PI, only two experiments were carried out: one experiment is the control run, and the other experiment is the perturbation run in which the total glacier area is increased to $0.70 \times 10^{6} \mathrm{~km}^{2}$ over both the Pamir Plateau and Himalayas (PI_T70; see Table 1). To obtain robust signals, all runs were continued for at least 110 years and the last 100 years of data were used for analyses.

\section{b. LBM and diagnosis of atmospheric dynamics}

A linear baroclinic model (LBM) was used to determine the response of the atmospheric circulation to the expansion of glaciers. The model consists of primitive equations linearized about the summer [June-August (JJA)] climatology obtained from the LGM and PI control runs, respectively. The model can well reproduce the summer circumglobal teleconnection of the Northern Hemisphere and has been used to study the driving forces of this teleconnection pattern (Lin et al. 2017; Yasui and Watanabe 2010). It has also been used to study the connection of mei-yu in China and baiu in Japan under the westerly jet background (Sampe and Xie 2010). Four sensitivity experiments were performed with this model. Three of these experiments are based on the basic state of LGM climatology, and the fourth experiment is based on PI climatology. The model is driven with prescribed diabatic heating (sum of latent and sensible heating) at all levels of the atmosphere. The heating is obtained by differentiating the respective term output from the perturbed runs and the control runs. The outputs from perturbed runs LGM_P35, LGM_H35, and LGM_T70 are used for the first three experiments. This allows one to investigate the possible roles that regional heat sources and sinks play in driving large-scale circulations in the Asian region. In particular, the dry version of the LBM model without moisture feedback is used in this study.

The LBM adopts a horizontal resolution of triangular spherical harmonic truncation 42 (T42) and 20 vertical sigma $(\sigma)$ levels and includes horizontal (vertical) diffusion, Rayleigh friction, and Newtonian damping. The diabatic heating outputs from the CESM model are interpolated linearly to this grid. The horizontal diffusion has a damping time scale of $6 \mathrm{~h}$ for the smallest wave, and the Rayleigh friction and Newtonian damping have a time scale of 0.5 days for $\sigma \geq 0.9$ and 1 day for $\sigma \leq 0.03$, and 20 days between them. Details of the model formulation are given in Watanabe and Kimoto (2000). To obtain the linear atmospheric response to the forcing in this study, we adopt a time integration method. The integration is continued up to 50 days, and the 30-day-mean results averaged over model days 20-49 are shown as the steady response to a prescribed diabatic heating forcing. The circulation response approaches the steady state after approximately day 15 .

\section{c. Surface mass balance of glaciers}

The surface mass balance of glaciers includes two parts: melting and accumulation. The latter is obtained by the annual precipitation, while the former can be estimated by the positive-degree-day (PDD) method (Huybrechts and T'Siobbel 1995). In glaciology, the PDD is the sum of all positive hourly temperatures over the year and is divided by 24 (hours). The unit is usually expressed as PDD or pdd, and sometimes also days ${ }^{\circ} \mathrm{C}$. When there are no units shown after the values, PDD or pdd is assumed. The hourly temperatures are obtained by assuming a normal distribution around the monthly mean, with a standard deviation of $5.5^{\circ} \mathrm{C}$. The standard deviation varies from $4.0^{\circ}$ to $8.0^{\circ} \mathrm{C}$ in different months and locations but generally takes small values. The PDD increases slightly with the standard deviation; for the Himalayas, the PDD increases by $6 \%$ when the standard deviation is increased from $5.5^{\circ}$ to $7.0^{\circ} \mathrm{C}$. However, the changes in PDD between the perturbation experiments and the control experiment are insensitive to the choice of the standard deviation. For each PDD, it is normally assumed that $3 \mathrm{~mm}$ of snow or $8 \mathrm{~mm}$ of ice can be melted, and $60 \%$ will be refrozen onto the ice surface (e.g., Tarasov and Peltier 1997, 1999).

\section{Results}

\section{a. The LGM climatology}

The simulated surface temperature for the LGM is shown in Figs. 2a-c. The globally averaged annual mean surface temperature is approximately $7.5^{\circ} \mathrm{C}$ colder than that of the PI temperature, which agrees with the latest estimate $\left(4.7^{\circ}-8.6^{\circ} \mathrm{C}\right.$; Snyder 2016$)$. The temperature decrease of between $2^{\circ}$ and $6^{\circ} \mathrm{C}$ is modest over the tropical regions, while it can be more than $30^{\circ} \mathrm{C}$ over the polar regions (Figs. 2d-f). The locations where the temperature decreases the most are where continental ice sheets developed (North America and northern Europe) and where sea ice expanded or thickened (mid- to highlatitude oceans). Over the Tibetan Plateau and the ASM region, the temperature decreases by $\sim 2^{\circ}-4^{\circ}$ and $\sim 3^{\circ}-6^{\circ} \mathrm{C}$ in the summer (defined as June-August) and winter (December-February), respectively. The global mean 


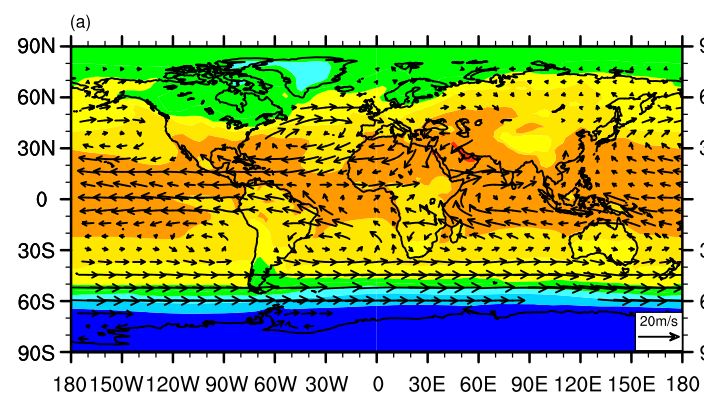

(d)

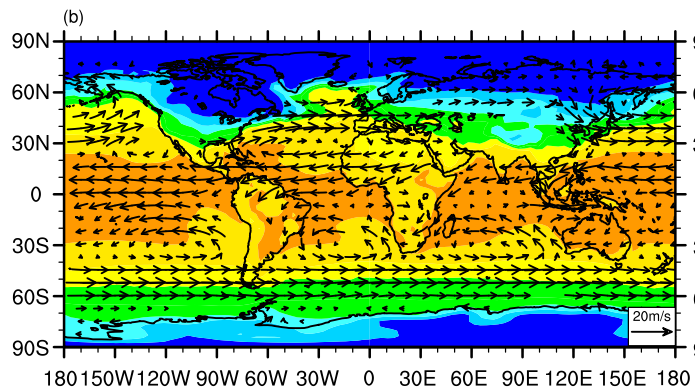

180150W120W 90W 60W 30W O 30E 60E 90E 120E 150E 180 (e)
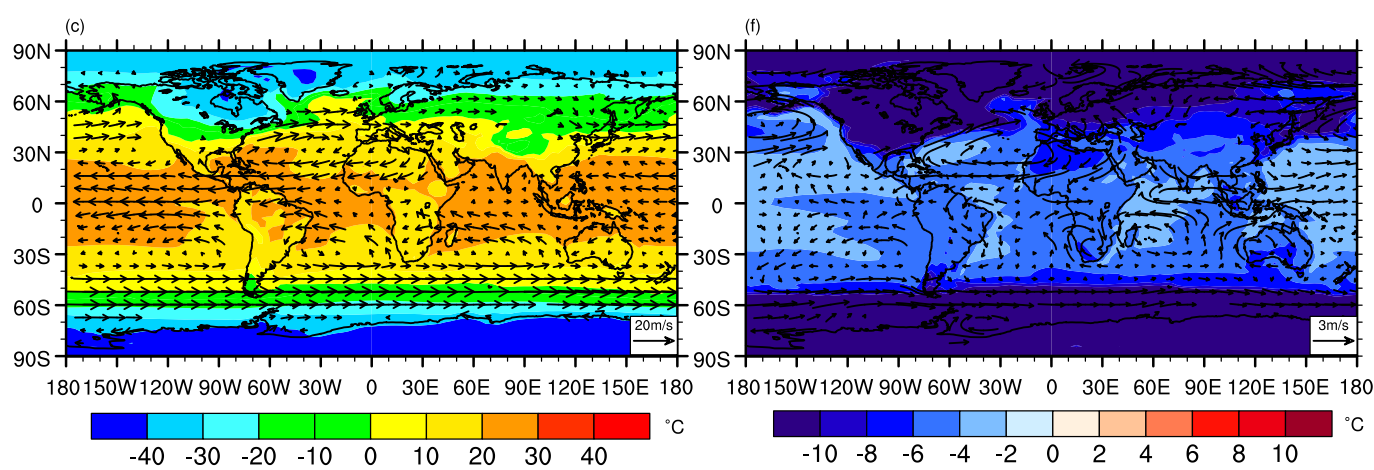

FIG. 2. (a)-(c) Surface temperature (shading) and 850-hPa winds (vectors) of the LGM control simulation and (d)-(f) their changes relative to the PI control simulation values during (top) JJA, (middle) DJF, and (bottom) annual mean. Nearly all the changes in (d)-(f) are significant at the 0.05 level.

SST has a cooling of $4.5^{\circ} \mathrm{C}$ relative to that of the PI, coincident with the multimodel mean $\left(4.5^{\circ} \pm 1.5^{\circ} \mathrm{C}\right)$ of the PMIP2 simulations, each of which has been bias corrected with respect to the reconstructed temperature (Annan and Hargreaves 2013).

The annually averaged global mean precipitation rate decreases from $\sim 2.9 \mathrm{~mm} \mathrm{day}^{-1}$ (model value) in PI to $2.4 \mathrm{~mm} \mathrm{day}^{-1}$ in the LGM, consistent with the large decrease in surface temperature. The precipitation rate decreases over most regions, especially the continents, but may increase significantly over some regions, which is mainly due to the shift or changes in the intertropical convergence zone (ITCZ) and the Northern Hemispheric storm track (Figs. 3d-f). Over Asia, the summer precipitation decreases greatly over the Arabian Peninsula $\left(2-5 \mathrm{~mm}_{\text {day }^{-1}}\right)$, the Arabian Sea $\left(>5 \mathrm{~mm} \mathrm{day}^{-1}\right)$, and the southern edge of the Tibetan Plateau $\left(2-5 \mathrm{~mm} \mathrm{day}^{-1}\right)$ and increases over northern
India $\left(\sim 2 \mathrm{~mm}_{\text {day }}{ }^{-1}\right)$, the Bay of Bengal $\left(\sim 5 \mathrm{~mm}_{\text {day }}{ }^{-1}\right)$, and the western North Pacific $\left(\sim 3-5 \mathrm{~mm} \mathrm{day}^{-1}\right)$. The winter precipitation changes little $\left(<1 \mathrm{~mm} \mathrm{day}^{-1}\right)$ over all of Asia, with the exception that it decreases significantly over the Bay of Bengal and the Maritime Continent $\left(\sim 3-5 \mathrm{~mm} \mathrm{day}^{-1}\right)$. Because of these changes, the modeled monsoonal region (the green area in Fig. 4), as defined in Wang and Ding (2008), expands into the southwestern part of the Bay of Bengal, western Pacific, and Japan but shrinks significantly over the Arabian Peninsula, Arabian Sea, and northern China compared to during the PI period (the red contour in Fig. 4). The expansion of Tibetan glaciers has a very slight influence on the modeled LGM monsoonal region (the yellow contour in Fig. 4), as will be discussed in section 3c.

The global pattern of precipitation change in CESM1.2 is similar to the multimodel-ensemble-mean change in the PMIP3 models (Yan et al. 2016). The decrease in summer 

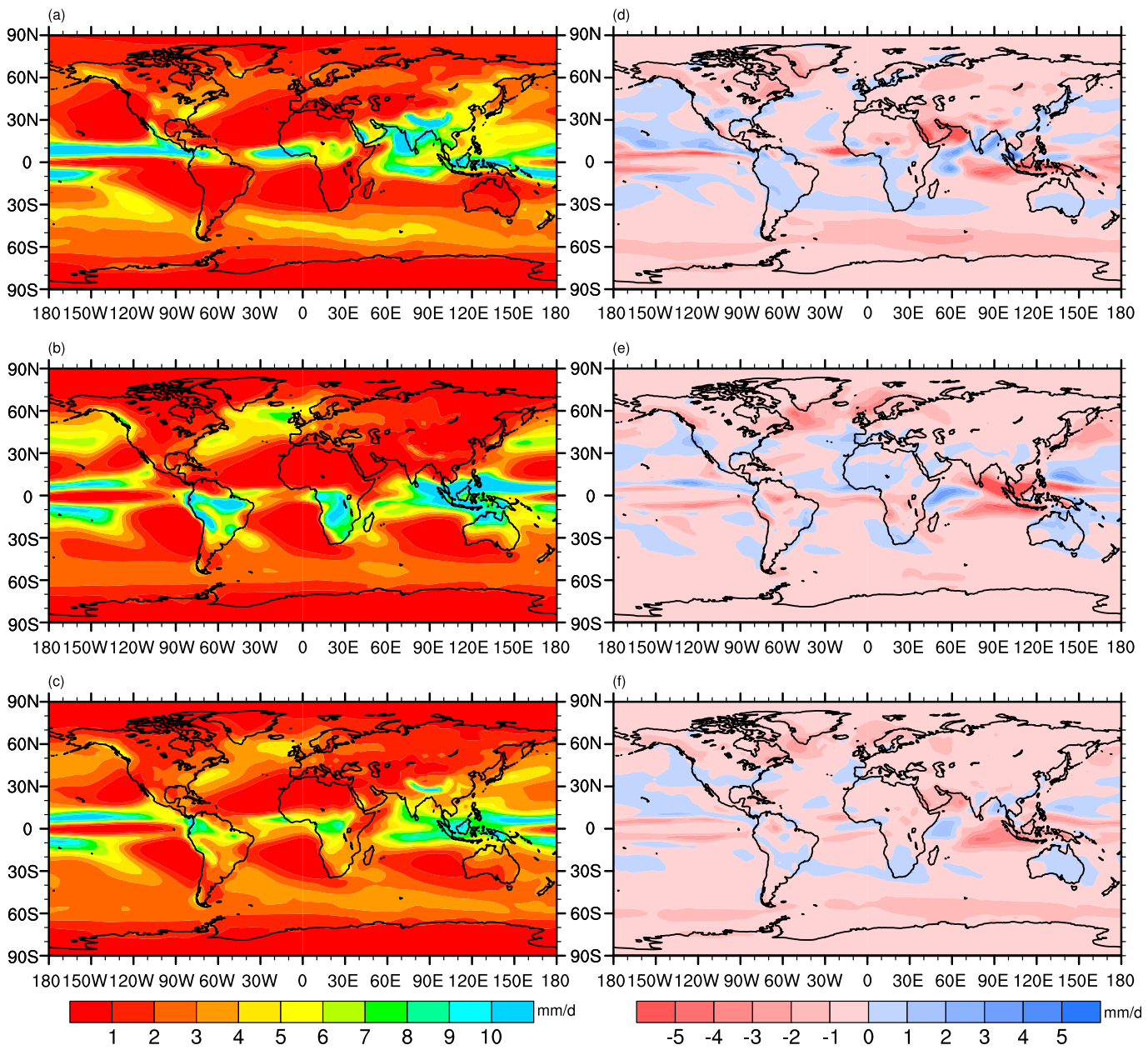

FIG. 3. As in Fig. 2, but showing the (a)-(c) precipitation rate of the LGM and (d)-(f) its change relative to the PI values are shown. Nearly all the changes in (d)-(f) are significant at the 0.05 level.

precipitation over the Arabian Peninsula and the Arabian Sea is clearly visible in Fig. 11 of Yan et al. (2016) and is associated with the strong northerly wind anomaly over this region (Fig. 2d). However, the increase in summer precipitation over the northern
India, the Bay of Bengal, southeastern China, and the western North Pacific during the LGM relative to the PI simulated here does not appear in the multimodelensemble mean. This may not be surprising because models generally have problems correctly simulating the

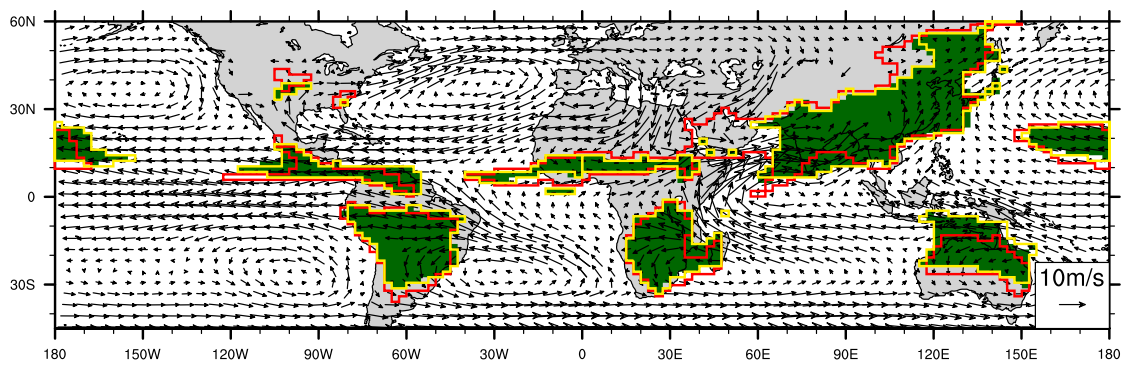

FIG. 4. The monsoonal region defined according to Wang and Ding (2008). The green color is the monsoonal region for the LGM obtained by the model. The areas outlined in yellow denote the new monsoonal region when glaciers on the Tibetan Plateau expanded (experiment T70). The areas outlined in red denote the monsoonal region for the PI. The $850-\mathrm{hPa}$ summer winds (vectors) for the LGM are also shown. 
(a):JJA

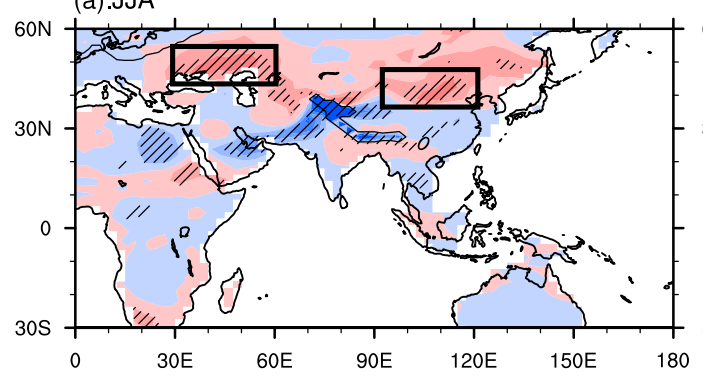

(b):DJF

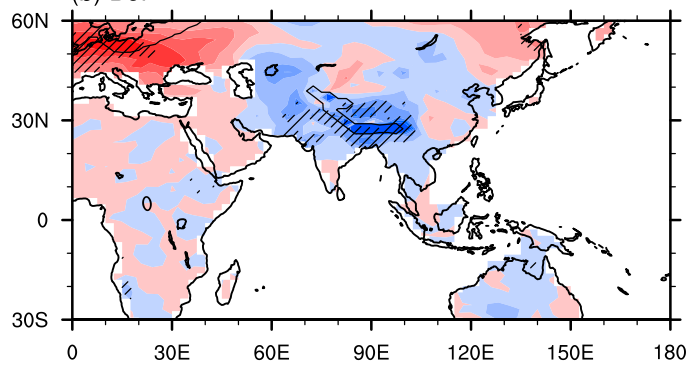

(c):AnnualMean

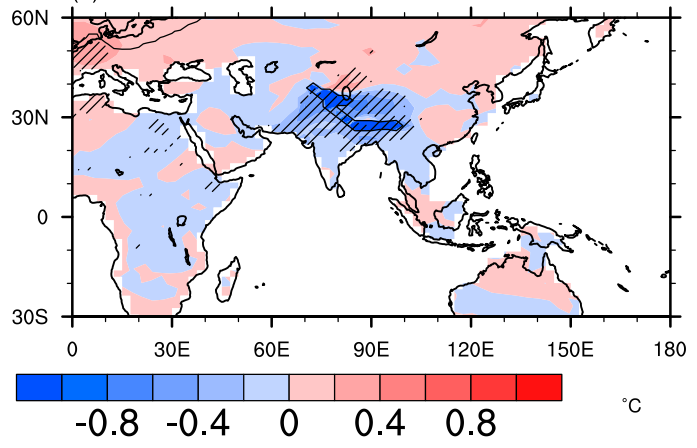

(d):JJA

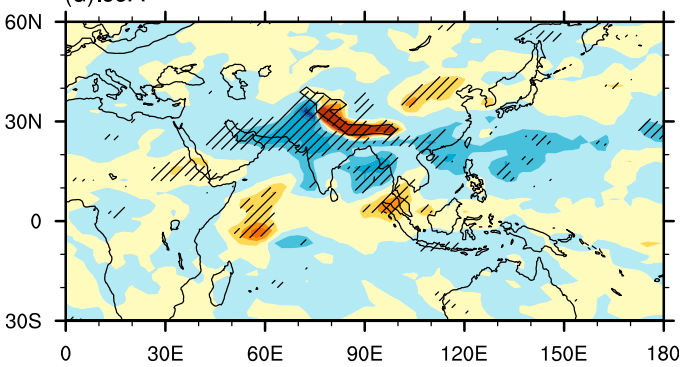

(e):DJF

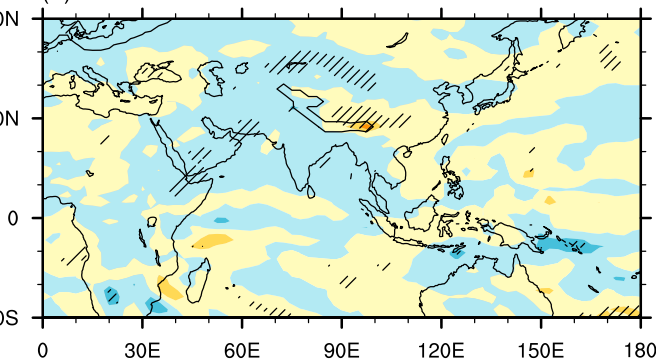

(f):AnnualMean

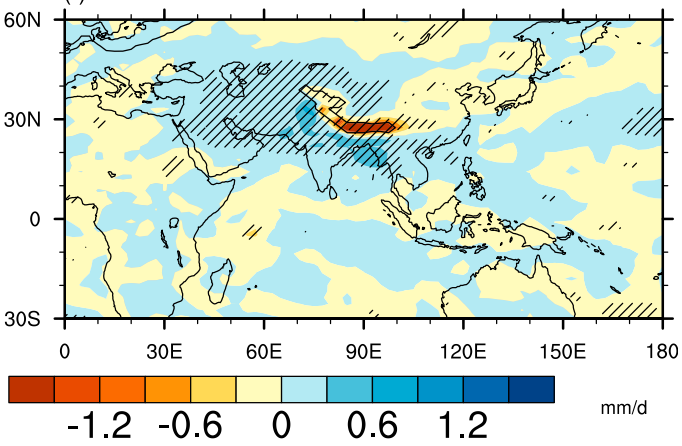

FIG. 5. Change in (a)-(c) surface temperature and (d)-(f) precipitation rate due to the addition of glaciers over the Tibetan region (Fig. 1c; experiment LGM_T70) during the LGM for (top) JJA, (middle) DJF, and (bottom) annual mean. Regions where the change is significant at the 0.05 level are hatched.

intensity of monsoonal precipitation over the western North Pacific (Lee and Wang 2014).

\section{b. Impact of glacial expansion on their own surface mass balance}

When the glacial area increases to $0.70 \times 10^{6} \mathrm{~km}^{2}$ over the Tibetan region (experiment LGM_T70) during the LGM, both the surface temperature and the precipitation rate decrease significantly over the glaciated region (Fig. 5). The annual mean surface temperature decreases by $\sim 3.5^{\circ} \mathrm{C}$ over both the Pamir region and Himalayas, but the change in the seasonal cycle is very different between the two regions (Fig. 6). The Pamir region has a much larger decrease in summer temperature $\left(-7^{\circ} \mathrm{C}\right)$ than winter temperature $\left(-1^{\circ} \mathrm{C}\right)$, while the Himalayas show the opposite $\left(-1.5^{\circ}\right.$ vs $-5^{\circ} \mathrm{C}$; Figs. $5 \mathrm{a}, \mathrm{b}, 6$, and 7$)$. In fact, the different local responses, as seen in Fig. 5 (most clearly seen in Figs. 5b and 5f), motivated us to separate the whole region into two parts (Figs. 1a,b) in the first place. Because surface melting of snow or ice mainly occurs in the summer, cooler summer temperatures increase the surface mass balance of glaciers and facilitate their expansion.

The PDDs of the whole year are 255 and 1357 for the Pamir region and Himalayas, respectively, in experiment LGM_T70. Compared to their values in the LGM control experiment, the annual PDDs decrease by $518(67 \%)$ and $496(27 \%)$, respectively. If $3 \mathrm{~mm}$ of snow can be melted per PDD and $60 \%$ of the melted snow refreezes, as is normally assumed, the cooling reduces annual snowmelt by 621 and $595 \mathrm{~mm}$ over the two regions, respectively. This is an underestimate because if there is no snow on the glacial surface, which is possible over part of the glacier, $8 \mathrm{~mm}$ of ice can be melted per PDD. 
(a)

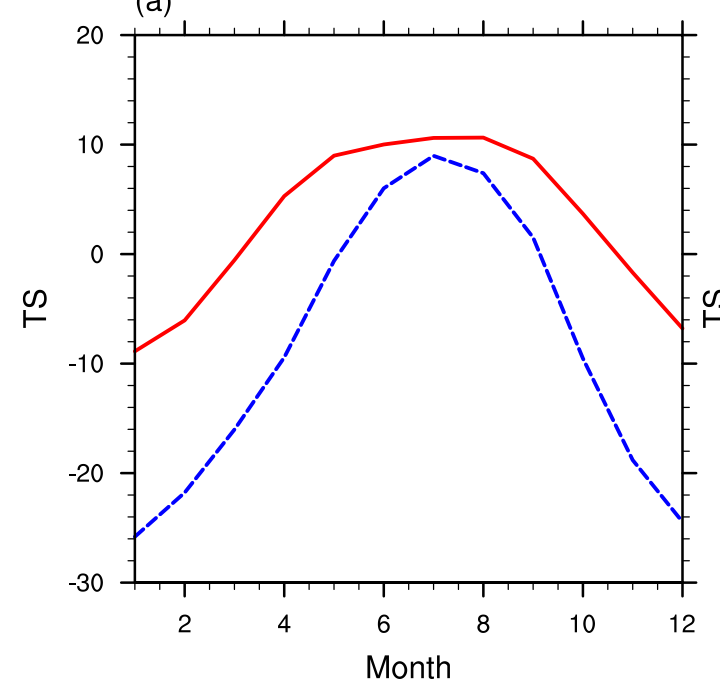

(b)

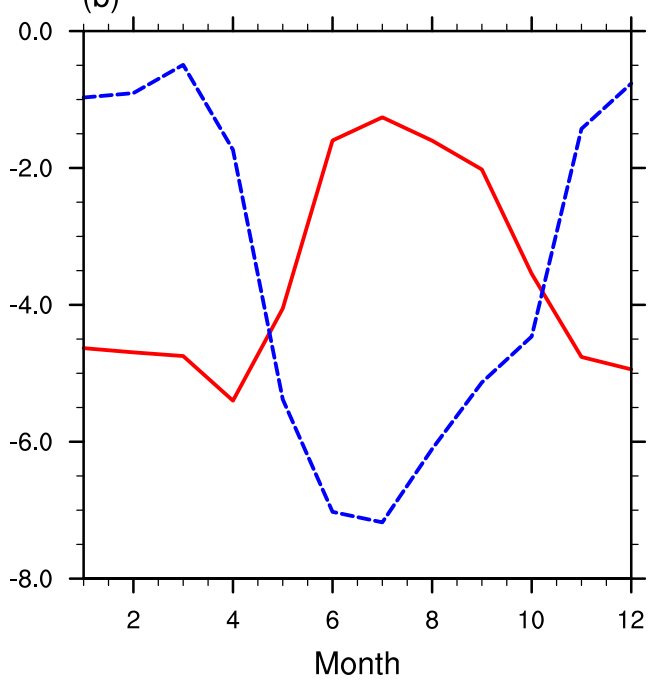

FIG. 6. Seasonal cycles of surface temperature in (a) the LGM control run and (b) their changes after the glaciers are expanded to $0.70 \times 10^{6} \mathrm{~km}^{2}$ (experiment LGM_T70 - LGM control). The blue dashed and red solid curves are the values averaged over the Pamir and Himalayan regions, respectively.

The surface mass balance of glaciers is determined by both the surface melting and precipitation. The annual mean precipitation decreases by 0.2 and $2.5 \mathrm{~mm}$ day $^{-1}$ over the Pamir region and Himalayas, respectively. Combined with the reduction in surface melting estimated above, the annual surface mass balance increases by $0.55 \mathrm{~m} \mathrm{yr}^{-1}$ over the Pamir region. In contrast, the reduction in precipitation overwhelms the reduction in surface melting over the Himalayas; the surface mass balance decreases by $0.32 \mathrm{myr}^{-1}$. Therefore, the expansion of glaciers over the Pamir region (Himalayas) can have a significant positive (negative) feedback on its own growth.

When the glacial area increases to $0.53 \times 10^{6} \mathrm{~km}^{2}$ (experiment LGM_T53) or $0.35 \times 10^{6} \mathrm{~km}^{2}$ (experiment LGM_T35), over the Tibetan region rather than to $0.70 \times 10^{6} \mathrm{~km}^{2}$, both the surface temperature and precipitation still decrease significantly over the glaciated regions (Table 1 ). The surface mass balance changes by 0.29 and $-0.13 \mathrm{~m} \mathrm{yr}^{-1}$ even for the experiment LGM_T35 over the Pamir Plateau and Himalayas, respectively, equivalent to an increase in glacial thickness of 1450 and $-650 \mathrm{~m}$ over 5000 years. This means that neglecting the change in temperature and precipitation due to glacial expansion when modeling the extent of Tibetan glaciers could induce large errors in the results.

\section{c. Changes in temperature and precipitation in other regions}

The glacial expansion in the LGM_T70 experiment also induces cooling in the nearby regions. In the summer, the most notable cooling occurs in the northwest Indian subcontinent $\left(0.3^{\circ}-0.8^{\circ} \mathrm{C}\right)$; weak cooling occurs in the interior of the Tibetan Plateau and northeastern Arabian Peninsula $\left(0.2^{\circ}-0.4^{\circ} \mathrm{C}\right.$; Fig. $\left.5 \mathrm{a}\right)$. In the winter, the cooling in the interior of the Tibetan Plateau is more significant $\left(0.4^{\circ}-0.8^{\circ} \mathrm{C}\right)$ than in the summer. A zonal belt near the southern slope of the Tibetan Plateau also experiences cooling $\left(0.2^{\circ}-0.4^{\circ} \mathrm{C}\right.$; Fig. $\left.5 \mathrm{~b}\right)$. Glacial expansion also induces warming near the border between Mongolia and China $\left(38^{\circ}-45^{\circ} \mathrm{N} ; 0.3^{\circ}-0.6^{\circ} \mathrm{C}\right)$ and eastern Europe $\left(0.2^{\circ}-\right.$ $\left.0.4^{\circ} \mathrm{C}\right)$ in the summer and central Europe $\left(\sim 1.0^{\circ} \mathrm{C}\right)$ in the winter. All of the changes are significant at the 0.05 level. The mechanism for such temperature changes is explored below in section 4 a.

The winter precipitation does not show any significant changes over Asia; although the changes in some regions pass the 0.05 significance level, the magnitude of change is very small $\left(<0.3 \mathrm{~mm} \mathrm{day}^{-1}\right.$; Fig. $\left.5 \mathrm{e}\right)$. The summer precipitation increases significantly over South Asia $\left(0.3-0.8 \mathrm{~mm} \mathrm{day}^{-1}\right)$. In contrast, the summer precipitation decreases significantly over central $\left(>0.6 \mathrm{~mm} \mathrm{day}^{-1}\right)$ and northern China $\left(0.3-0.6 \mathrm{~mm} \mathrm{day}^{-1}\right.$; Fig. $\left.5 \mathrm{~d}\right)$. If the summer precipitation rate is used to define the intensity of the SASM, then the results mean that the SASM becomes stronger while the EASM becomes weaker when the glaciers expanded over the Tibetan Plateau during the LGM. Note that the summer is defined herein as June to August rather than May to September, which is as often used for monsoon studies (Wang and Ding 2008; Wang et al. 2017), to more clearly show the change in precipitation; the change will decrease if the length of summer is extended to five months, but the pattern is the same 
(a):JJA

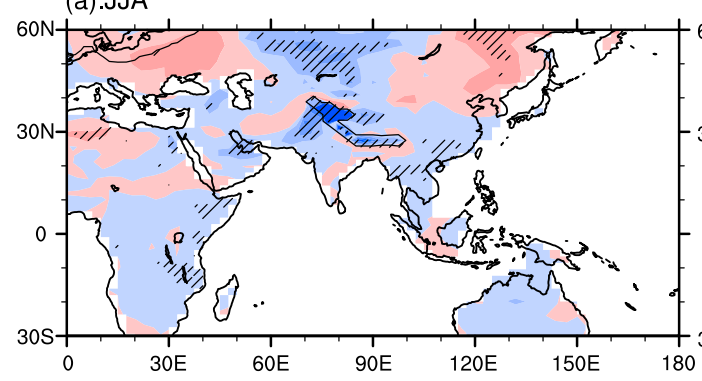

(b):JJA (c): JJA

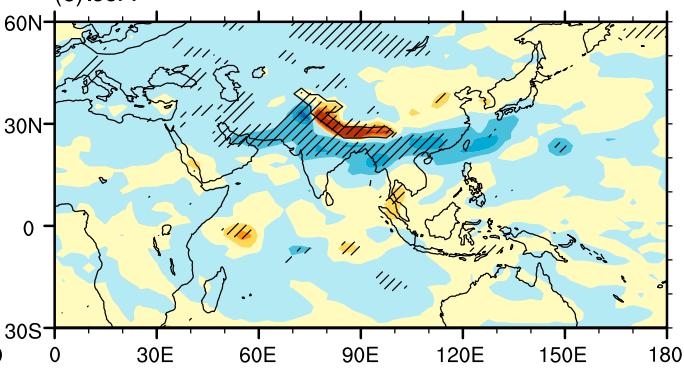

(d): :JJA

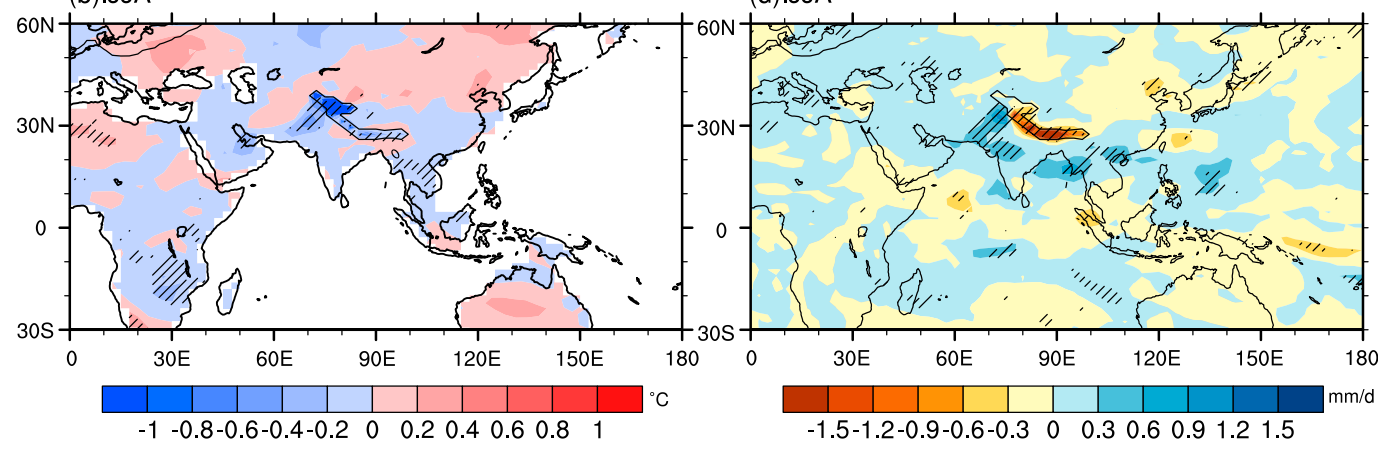

FIG. 7. Change in (a),(b) summer surface temperature and (c),(d) precipitation rate due to the addition of glaciers over the Tibetan region (Fig. 1c) during the LGM for experiments (top) LGM_T53 and (bottom) LGM_T35, respectively. Regions where the change is significant at the 0.05 level are hatched.

(not shown). The influence of glacial expansion on the extent of the monsoonal region is small; the monsoonal region shrinks slightly between $38^{\circ}$ and $44^{\circ} \mathrm{N}$ and between $110^{\circ}$ and $12^{\circ} \mathrm{E}$ in the North China and one grid point near $\left(37^{\circ} \mathrm{N}, 108^{\circ} \mathrm{E}\right)$ (Fig. 4).

The precipitation in the interior of the Tibetan Plateau increases slightly $\left(<0.3 \mathrm{~mm} \mathrm{day}^{-1}\right)$ in summer and decreases slightly (also $<0.3 \mathrm{~mm} \mathrm{day}^{-1}$ ) in winter, which together yields a small net increase in the annual precipitation (Figs. 5d-f). Combined with small cooling in this region (Figs. 5a-c), this result implies that the expansion of glaciers over the Pamir Plateau and the Himalayas probably had limited influences on glacial growth in the interior.

If the glaciers over Tibet were smaller, that is, $0.53 \times$ $10^{6} \mathrm{~km}^{2}$ (experiment LGM_T53) and $0.35 \times 10^{6} \mathrm{~km}^{2}$ (experiment LGM_T35), their impact on both temperature and precipitation decreases proportionally. For both cases, the change in summer precipitation over central and northern China is negligible; the increase in summer precipitation over South Asia persists for the LGM_T53 case but diminishes for the LGM_T35 case (Fig. 7). The temperature change does not pass the significance test for the LGM_T35 case, but the pattern is still similar to that of the LGM_T70 case. The changes in winter temperature and precipitation are similarly weaker for the LGM_T53 and LGM_T35 cases than for the LGM_T70 case and therefore are not shown.

\section{d. Influence of individual glaciers over the Pamir region and Himalayas}

The influence of glacial expansion over the Pamir region (experiment LGM_P35) is distinctly different from that of the glacial expansion over the Himalayas (experiment LGM_H35). The influence on summer precipitation over surrounding regions seen in experiment LGM_T70 is primarily due to the glacial expansion over the Himalayas (comparing Figs. 8 and 9). The two experiments (LGM_P35 and LGM_H35) have similar influences on surface temperature, with LGM_H35 having a larger amplitude than LGM_P35, especially in winter. Again, it is seen that the glacier over the Pamir region has a larger influence on surface temperature over the glaciated region in the summer than in the winter (Figs. 8a,b), while the glacier over the Himalayas has a larger influence in the winter than in the summer (Figs. 9a,b).

\section{Discussion}

\section{a. Mechanism analysis}

Although the reduction in surface temperature and precipitation over glaciated regions seems to be straightforward to understand, it is puzzling that the glacier over the Himalayas has a larger impact on surface temperature during winter than summer (Figs. 5a,b). Figure 10 shows 
(a):JJA

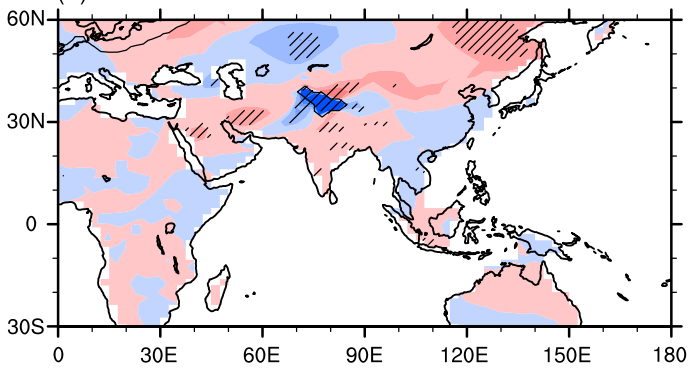

(b):DJF (c) :JJA

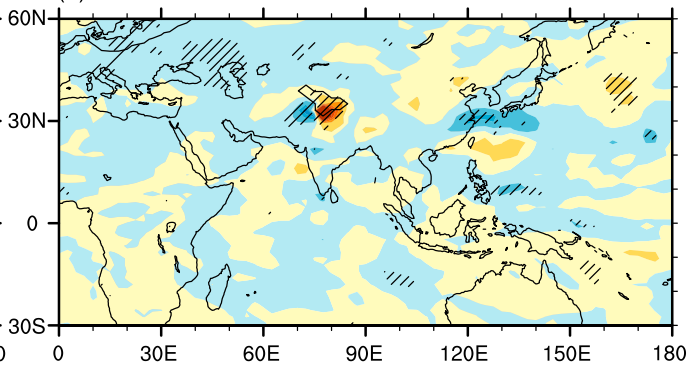

(d) :DJF

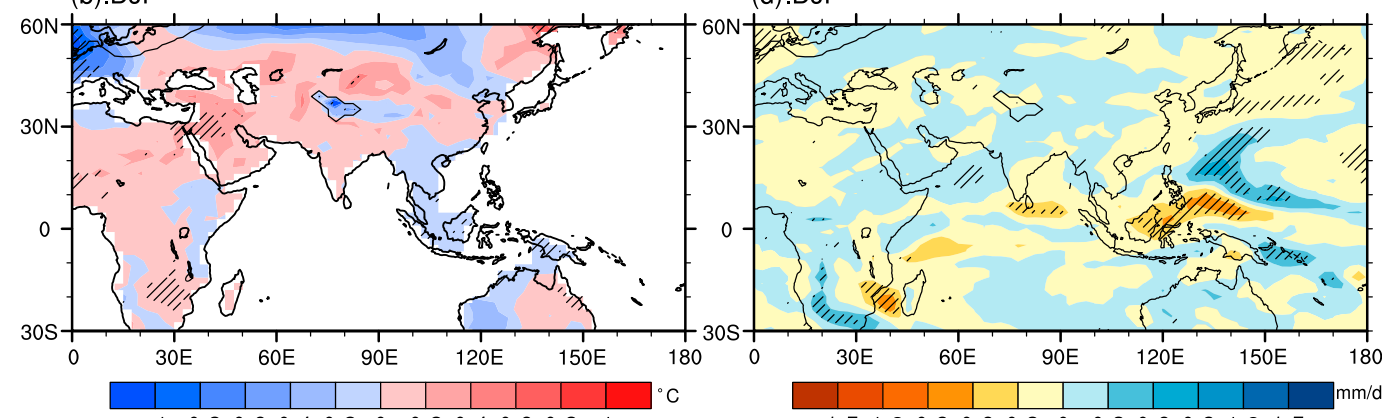

$\begin{array}{llllllll}-1 & -0.8-0.6-0.4-0.2 & 0 & 0.2 & 0.4 & 0.6 & 0.8 & 1\end{array}$

-1.5-1.2-0.9-0.6-0.3 000.30 .60 .91 .21 .5

FIG. 8. Change in (a),(b) surface temperature and (c),(d) precipitation rate due to addition of glaciers over the Pamir Plateau (Fig. 1a; experiment LGM_P35) during the LGM for the Northern Hemisphere (top) summer and (bottom) winter. Regions where the change is significant at the 0.05 level are hatched.

that the addition of glaciers over the Pamir region increases the surface albedo significantly during summer but does not have any effect during winter. This is understandable since the region is already covered by snow during winter in the control run; the addition of glacier does not increase the surface albedo or induce cooling. Over the Himalayas, the addition of glaciers increases the surface albedo during both summer and winter.
(a):JJA

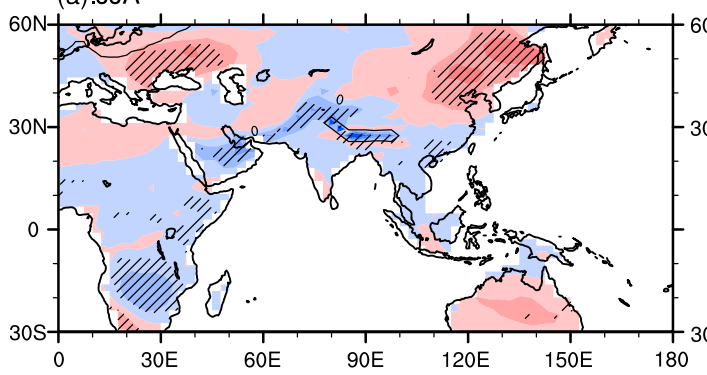

(b):DJF (c) :JJA

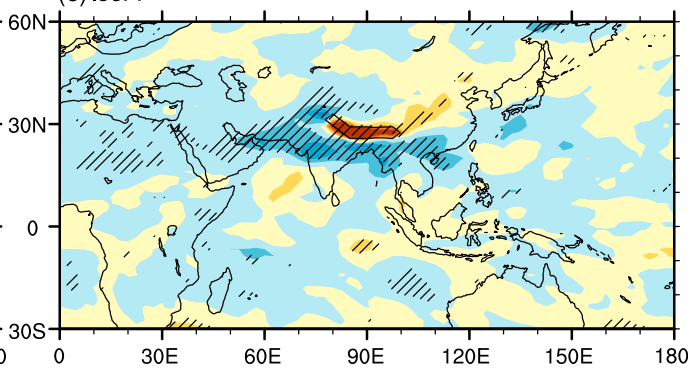

(d):DJF

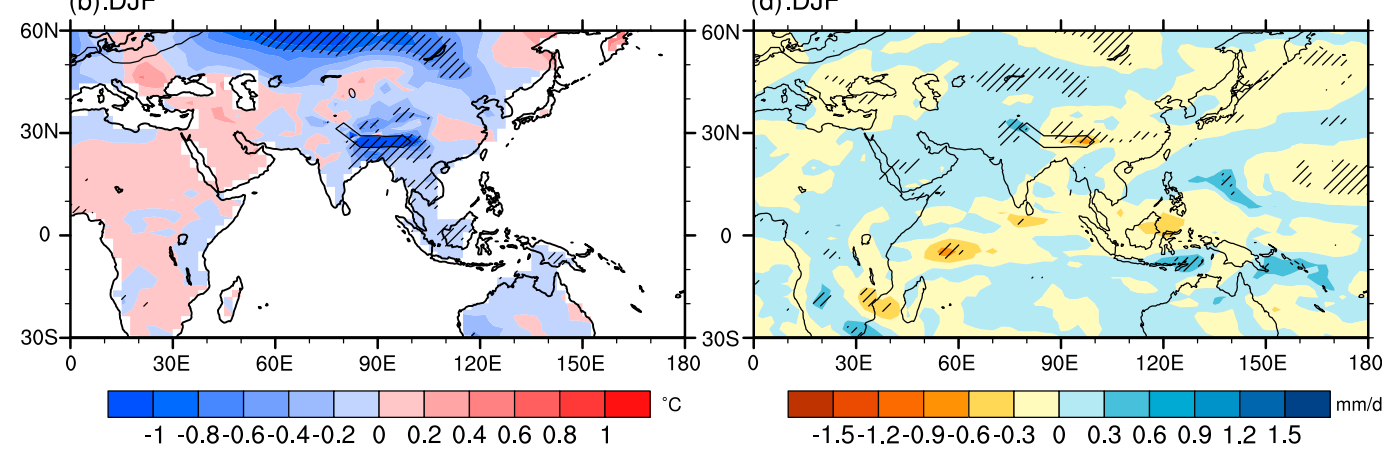

FIG. 9. Change in (a),(b) surface temperature and (c),(d) precipitation rate due to the addition of glaciers over the Himalayas (Fig. 1b; experiment LGM_H35) during the LGM for the Northern Hemisphere (top) summer and (bottom) winter. Regions where the change is significant at the 0.05 level are hatched. 

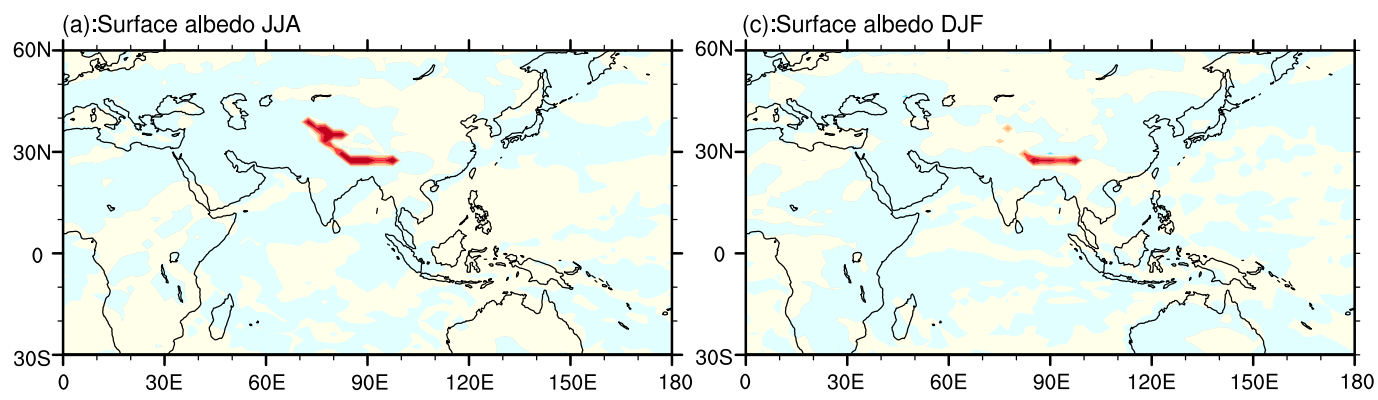

(b):Planetary albedo JJA

(d):Planetary albedo DJF

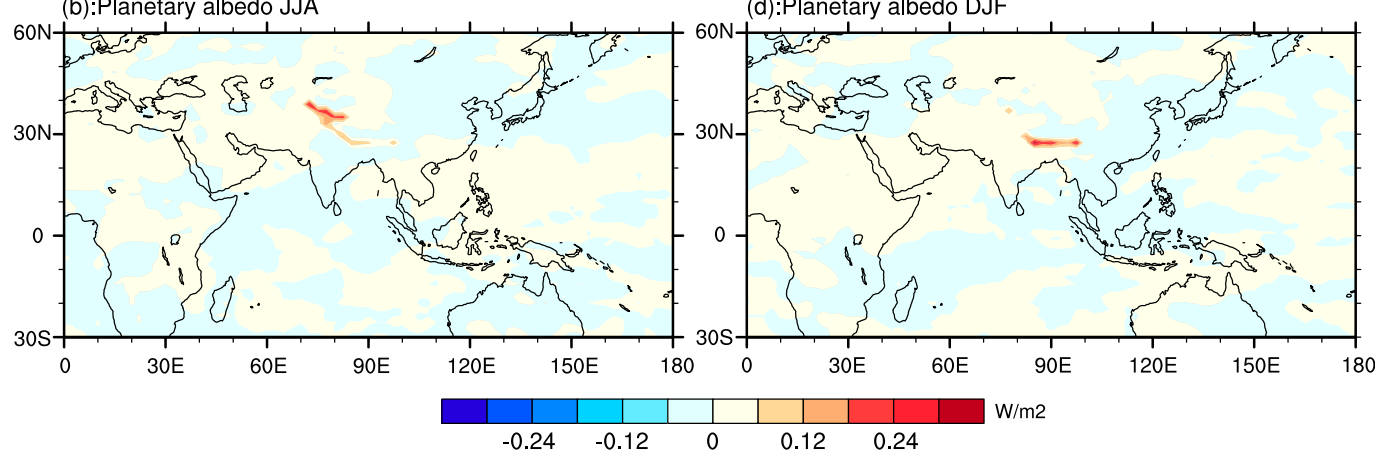

FIG. 10. The change in (a),(c) surface albedo and (b),(d) planetary albedo due to glacial expansion over the Tibetan region (experiment LGM_T70) during (left) summer and (right) winter.

However, because the Himalayan region is very cloudy during the summer, the change in surface albedo here does not have a significant impact on the radiative fluxes received at the surface and thus the surface temperature. This can be inferred from the change in surface and planetary albedos due to glacial expansion (Fig. 10); the surface albedo over the Himalayas increases significantly, but the planetary albedo changes little in summer. Therefore, the glaciers over the Himalayas have a greater impact on the surface temperature during winter than summer.

The addition of glaciers reduces both the sensible and latent heat fluxes in summer as expected, with values of approximately $20 \mathrm{~W} \mathrm{~m}^{-2}$ (Fig. 11). It is
(a):Sensible heat flux JJA

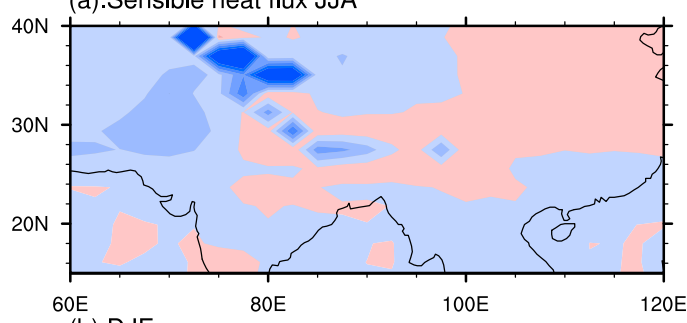

(b):DJF

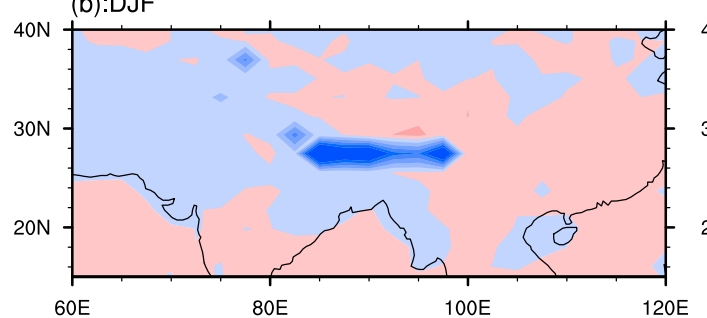

$60 \mathrm{E}$ (c): Latent heat flux JJA

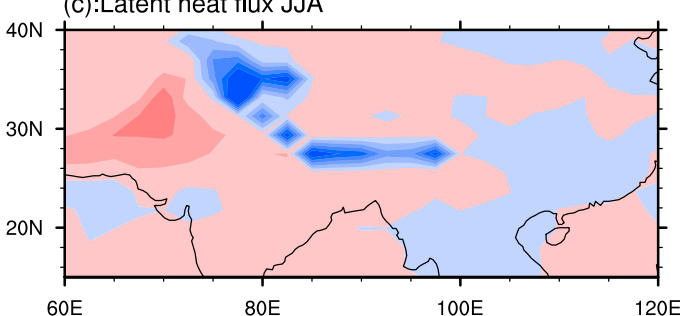

(d):DJF

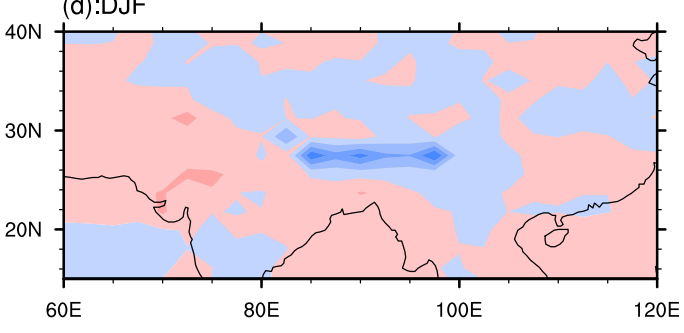

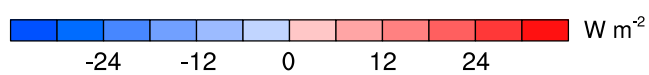

FIG. 11. The change in (a),(b) sensible heat flux and (c),(d) latent heat flux due to glacial expansion over the Tibetan region (experiment LGM_T70) during (top) summer and (bottom) winter. 

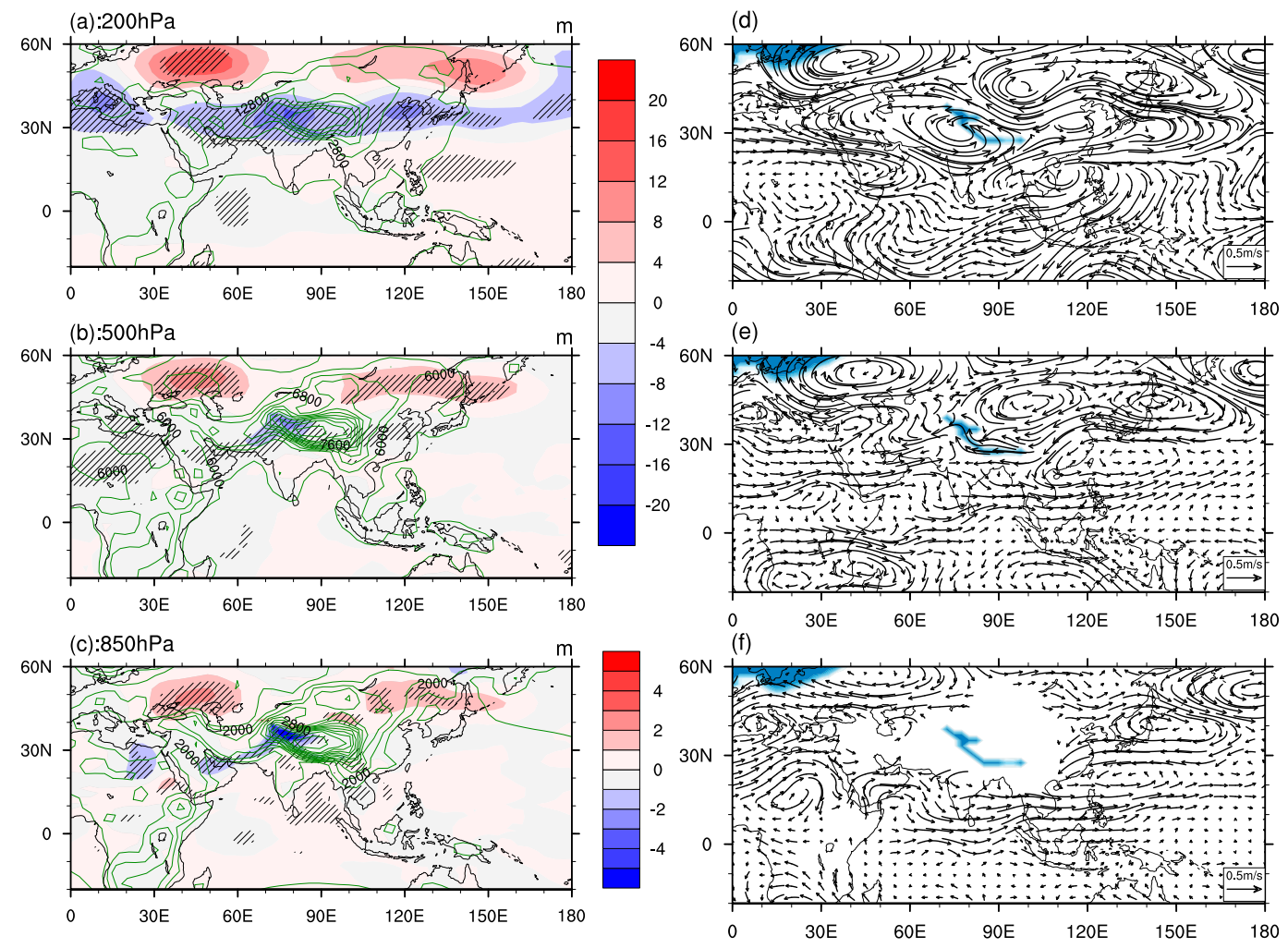

FIG. 12. Change in (left) geopotential height and (right) winds in summer on the (a) 200-, (b) 500-, and (c) 850-hPa isobaric surfaces due to expansion of glaciers (experiment LGM_T70). The green curves in (a)-(c) are the geopotential heights in the LGM climatology. Note that (a) and (b) share a color bar, but (c) uses a different color bar. The dark blue patches in (d)-(f) are the ice sheets or glaciers.

interesting to note that although the temperature change and the associated change in sensible heat flux during summer is small over the Himalayas (Figs. 4a and 10a), the change in latent heat flux is relatively large (peak values $>20 \mathrm{~W} \mathrm{~m}^{-2}$ ). This is why the glaciers over this region can have a significant influence on the ASM despite its weak influence on summer surface temperature (Fig. 9). The reduction in surface fluxes perturbs the atmospheric pressure and winds, which in turn induce changes in surface temperature and precipitation in nearby regions. In this study, the perturbations are too small to have a significant influence in remote regions.

The change in surface temperature in Europe and northern Asia (Figs. 5a,b) can be understood by looking at the changes in geopotential height and winds. Consistent with the reduction in surface heat fluxes (Fig. 11), the South Asian high (SAH) weakens during summer (Fig. 12a). This triggers positive pressure anomalies in the Northern Hemisphere westerlies (Figs. 12a-c), which induce near-barotropic anomalous anticyclones to both the northwest and northeast of the SAH. The one in the west acts to weaken the westerly of the control run. The westerlies advect cold air from west to east
(Fig. 2a), the weakening of which warms the summer temperature of the lower atmosphere by $\sim 0.26^{\circ} \mathrm{Cday}^{-1}$ in eastern Europe (the black box on the left in Fig. 5a). Correspondingly, the sensible and latent heat fluxes from the land to atmosphere decrease by 0.98 and $0.28 \mathrm{~W} \mathrm{~m}^{-2}$, respectively. The warming near the border between Mongolia and China (the black box on the right in Fig. 5a) may be attributed to the reduction in low cloud (as can be inferred from the precipitation decrease there; Fig. 5d); the net shortwave radiative flux received at the surface increases by an average of $0.50 \mathrm{~W} \mathrm{~m}^{-2}$ over the summer and the region. The temperature changes in winter can be similarly understood from the changes in winds and clouds (not shown).

The change in summer precipitation can also be partially understood from the change in lower- to midtropospheric winds; a weak anomalous anticyclone is induced around the Tibetan Plateau by glaciers (Fig. 12e). This anticyclone reduces the water vapor transport toward central and northeastern China and increases transport toward northern India. However, the picture is not so clear because the change in precipitation is a large heat source/sink in the lower to middle atmosphere and 

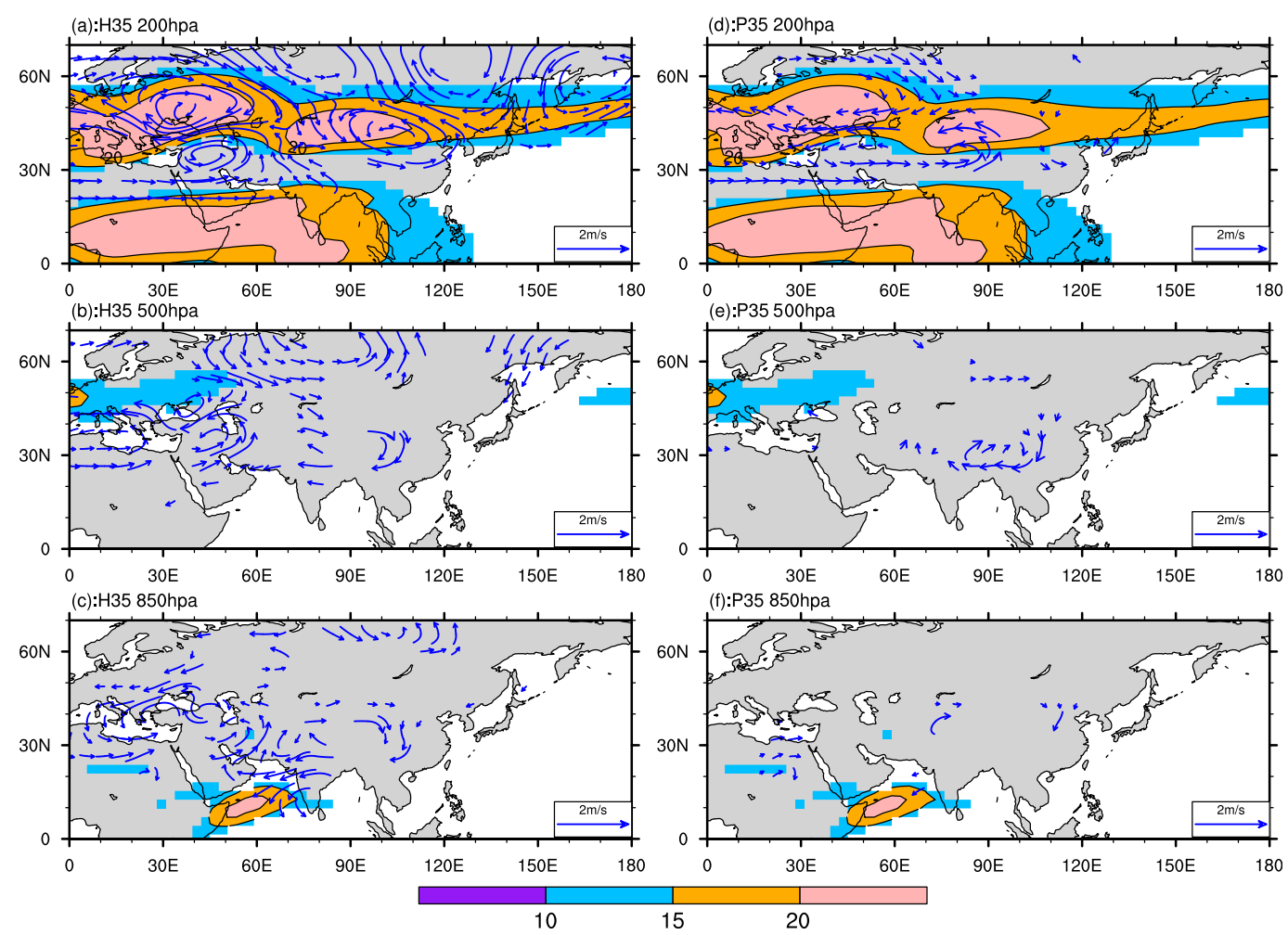

FIG. 13. The anomalous summer winds at (top) 200, (middle) 500 and (bottom) $850 \mathrm{hPa}$ induced by the addition of glaciers over the (a)-(c) Himalayas and (d)-(f) Pamir region. These are the direct responses of the circulation calculated by the LBM, which does not include moist processes. The filled contours show the background wind speed, indicating the centers of jets. The units for both the vectors and contours are $\mathrm{m} \mathrm{s}^{-1}$.

perturbs the circulation there; the direct influence of the glaciers on the winds is therefore largely masked. To see the direct influence of glaciers on the winds, a dry atmospheric dynamic model is driven using the anomalous sensible and latent heat fluxes over the glaciers obtained in experiments LGM_P35 and LGM_H35, respectively. Without moist processes involved, the anomalous anticyclonic circulation around the Tibetan Plateau is clearly seen in the low-level winds (Fig. 13). Glacial expansion over Himalayas indeed has a stronger influence on atmospheric circulation than that over the Pamir region, most notably in the lower atmosphere (Figs. 13c,f). This is probably because the former is closer to the main monsoonal regions of Asia.

Convergence of anomalous winds in Figs. 13a-c is seen over the Indochina Peninsula, northwestern India, and the Arabian Sea (Fig. 14a). Strong anomalous convergence of winds is also seen in central northern China, but the summer precipitation actually decreases (Fig. 9c). This is because the convergence of winds does not necessarily mean there is convergence of moisture. The actual anomalous moisture convergence (Fig. 14b) in experiment LGM_H35 is consistent with the anomalous change in summer precipitation (Fig. 9c). Note that the anomalous westerlies between $0^{\circ}$ and $20^{\circ} \mathrm{N}$ over southern Asia, as seen in Figs. $12 \mathrm{f}$ and $14 \mathrm{~b}$, are not present in Fig. 13c, which probably means that feedback is induced by the anomalous precipitation over the northern region rather than the westerly region.

The pattern of precipitation change obtained in this study is very similar to those obtained in the previous studies that perturbed the surface fluxes over the Tibetan Plateau in an idealized form. For example, $\mathrm{Lu}$ et al. (2018) reduced the surface albedo of the entire Tibetan Plateau to simulate the climate impact of a warming Tibetan Plateau. The pattern of precipitation change was almost identical to that shown in Fig. $5 \mathrm{~d}$ in this study except the sign is the opposite (see their Fig. 8b). Their study was done using the fully coupled CESM1.2, and the small change in sea surface temperature justifies the use of the atmosphere-only model as was carried out here. Wu et al. (2016) reduced the sensible and latent heat fluxes over the entire Tibetan Plateau using a completely different model. Their simulated changes in precipitation (see their Figs. 3b and 4b) had similar patterns to those obtained herein but with much larger amplitudes. However, these experiments were all performed under present-day climate conditions. Therefore, 

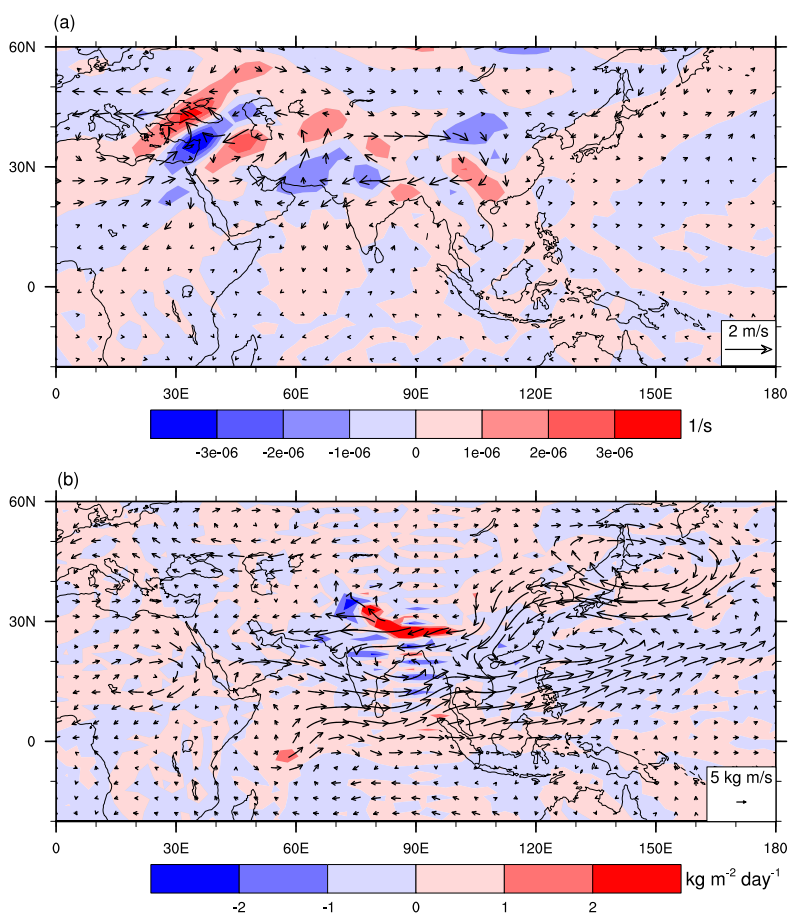

FIG. 14. (a) The convergence of anomalous winds obtained by the LBM for experiment LGM_H35 (Figs. 13a-c) and (b) the anomalous moisture transport (vectors) and convergence of moisture (colors) obtained by CAM4 for experiment LGM_H35. Convergence in (a) is calculated for the vertically averaged winds and in (b) for the vertically integrated moisture over the whole atmospheric column. Negative values indicate convergence.

it is interesting to see whether the influence of glacial expansion on climate is similar between the LGM and PI.

\section{b. Influence of glacial expansion under a preindustrial climate}

For the PI, adding glaciers over the Tibetan Plateau also cools the surface temperature over glaciated regions as would be expected; the glaciers over the Himalayas have a stronger cooling effect during winter than summer, which is similar to the LGM results (Figs. 15a-c). However, the PI's influence on the climate of nearby regions seems to be weaker than the influence of the LGM in terms of both temperature and precipitation. In particular, there is no significant change in summer precipitation in central and northeastern China; the increase in southern Asia also has a much smaller spatial extent and smaller amplitude than that of the LGM (comparing Figs. 15d and 5d). This indicates that, at least for small perturbations as applied herein, the climate responses during the LGM and PI may be quantitatively quite different.

The boundary conditions for the LGM and PI are different in four ways: 1 ) there are two additional large ice sheets over North America and northwestern Europe during the LGM, 2) the sea surface temperature is different (Fig. 2), 3) the orbital configuration is different, and 4) the greenhouse gas concentrations are different. They all affect the basic atmospheric circulation patterns and therefore the response to glacial expansion over the Tibetan Plateau. Preliminary results of experiments in which only a single factor is changed each time show that all factors contribute to the different climate responses to glacier expansion between the LGM and PI (not shown). A detailed analysis is difficult and is not pursued further due to the weak signals in both temperature and precipitation; further analyses should be conducted in the future for stronger perturbations such as a full glaciation of the Tibetan Plateau.

\section{c. Uncertainties and implications}

The SST of the LGM is specified here as a boundary condition, but it could be different from the real values. As a crude test of the sensitivity of the main results to this boundary condition, the SST from PI in experiment PI_control is specified for the experiments LGM_control and LGM_T70. The changes in temperature and precipitation between these two experiments (not shown) are very similar to those in Fig. 5, indicating that the results are not sensitive to the uncertainty in SST.

Usually, only the annual mean temperature and precipitation are reconstructed for the LGM (e.g., Annan and Hargreaves 2013). Taking the temperature as an example, the uncertainty is approximately $2^{\circ} \mathrm{C}$ over the land area around the Tibetan Plateau (see Fig. 3 of Annan and Hargreaves 2013). This is much larger than the temperature change induced by glacial expansion over the Tibetan Plateau, which is generally $<0.6^{\circ}$ and $<0.4^{\circ} \mathrm{C}$ in most places (Fig. 5c). Similarly, the impact of glacial expansion on annual precipitation is also small. Therefore, our results may tell us how temperature and precipitation would have changed if the Tibetan glaciers expanded during the LGM, but in practice, they are not able to improve the matching between the model simulations and reconstructions outside the Tibetan region. Our results do show that the surface mass balance of glaciers would have been impacted strongly if the glaciers expanded. Please note that the results here are obtained with a single model, and the uncertainties in the results due to possible model deficiency should be explored in the future.

\section{Conclusions}

The influence of glacial expansion over the Tibetan Plateau and its surrounding areas on climate during the LGM is studied using an atmospheric general circulation 
(a):JJA

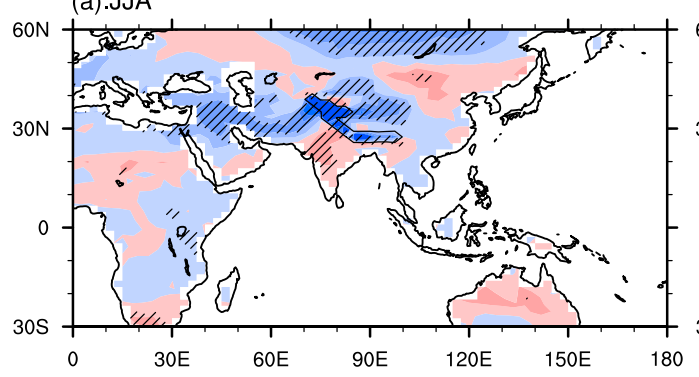

(b):DJF

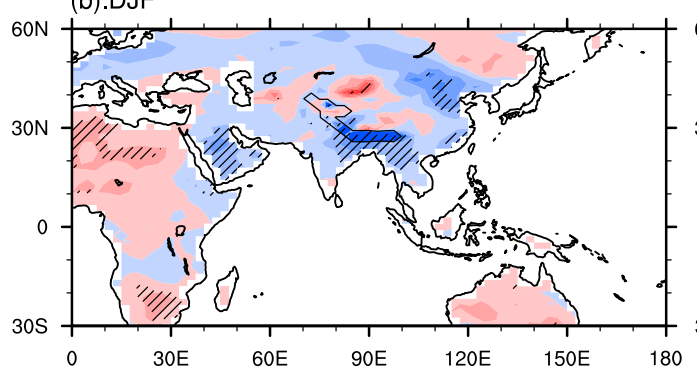

(c):AnnualMean

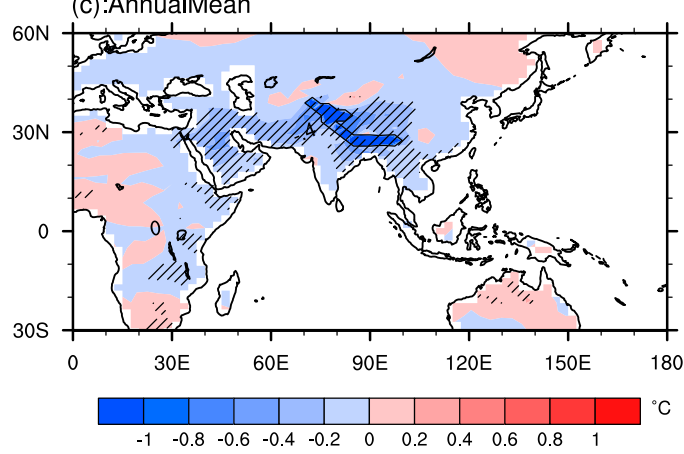

(d):JJA

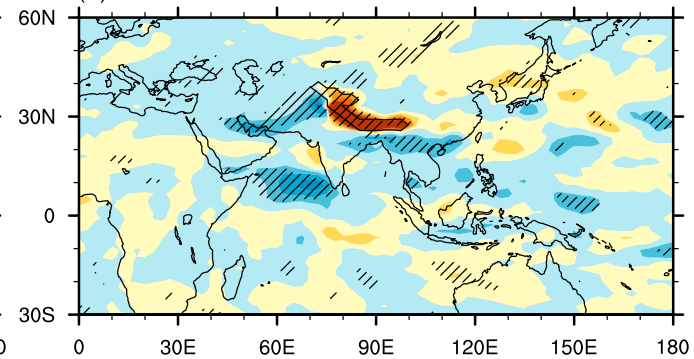

(e):DJF
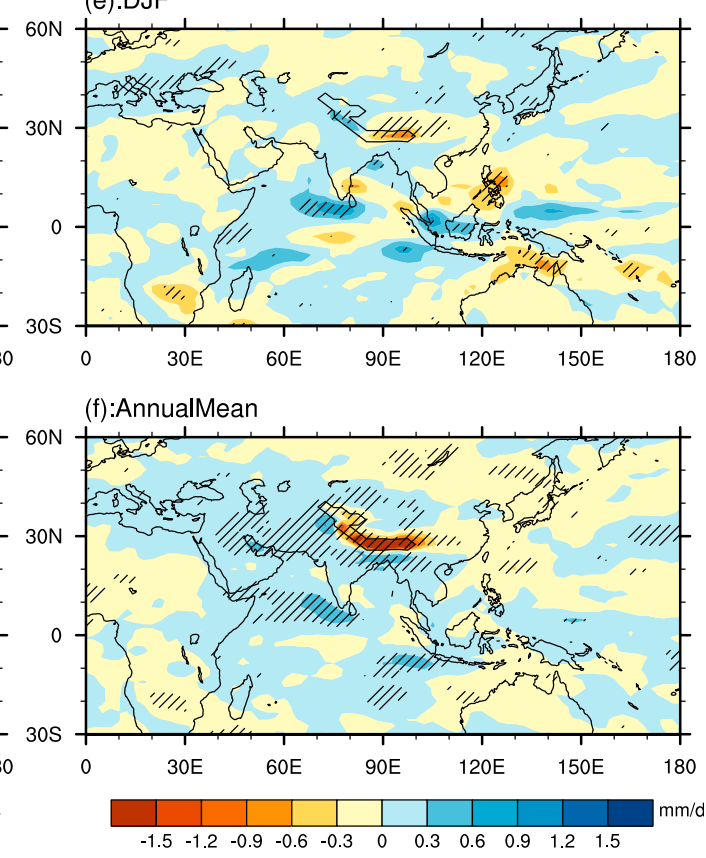

FIG. 15. As in Fig. 5, but for the change in (a)-(c) surface temperature and (d)-(f) precipitation rate during the PI (due to the addition of $0.70 \times 10^{6} \mathrm{~km}^{2}$ of glaciers over the Tibetan Plateau) for (top) JJA, (middle) DJF, and (bottom) annual mean. Regions where the change is significant at the 0.05 level are hatched.

model, CAM4, coupled to a land surface model, CLM4. Because of the uncertainty in the total glacial area over the Tibetan Plateau during the LGM, the following three values are tested: $0.70 \times 10^{6}, 0.53 \times 10^{6}$, and $0.35 \times 10^{6} \mathrm{~km}^{2}$. The glaciers are divided into two parts: the Pamir Plateau and Karakoram Mountains and the Himalayas. When a total of $0.70 \times 10^{6} \mathrm{~km}^{2}$ of glaciers is placed on the Tibetan Plateau, the annual mean surface temperature decreases by approximately $3.5^{\circ} \mathrm{C}$ over both the Pamir and Himalayan regions, while the precipitation decreases by $0.2 \mathrm{~mm} \mathrm{day}^{-1}(10 \%)$ and $2.5 \mathrm{~mm} \mathrm{day}^{-1}(24 \%)$ over the two regions, respectively. Corresponding to such changes in climate, the surface mass balance of glaciers increases by $0.55 \mathrm{~m} \mathrm{yr}^{-1}(280 \%)$ and $-0.32 \mathrm{~m} \mathrm{yr}^{-1}(-20 \%)$ over the Pamir and Himalayan regions, respectively, meaning that the glacier expansion over the Pamir region will enhance glacial growth, while the glacial expansion over the Himalayas will slow down its growth. The surface mass balance increases by 0.29 and $-0.13 \mathrm{~m} \mathrm{yr}^{-1}$ over Pamir and Himalayan regions, respectively, even if the glacier area is only increased by $0.35 \times 10^{6} \mathrm{~km}^{2}$. Therefore, the expansion of the Tibetan glaciers has a large feedback to glacier growth. Omission of this feedback in previous glacier modeling studies could cause large errors in the simulated glacier extent.

In the LGM_T70 (paleoglacier area is set as $0.70 \times 10^{6} \mathrm{~km}^{2}$ ) experiment, the expansion of glaciers over the Pamir region cools the local summer temperature by $7^{\circ} \mathrm{C}$, while the winter temperature only cools by $1^{\circ} \mathrm{C}$. The influence in winter is weaker because the land surface is already covered by snow, and the addition of glaciers does not affect the surface albedo. In contrast, the expansion of glaciers over the Himalayas cools the local winter temperature $\left(\sim 5^{\circ} \mathrm{C}\right)$ more than the summer temperature $\left(\sim 1^{\circ} \mathrm{C}\right)$. This is because the region is very 
cloudy in summer, and the addition of glaciers does not change the solar radiation received at the surface much.

The expansion of glaciers on the Tibetan Plateau (LGM_T70 experiment) increases summer precipitation by $0.3-0.8 \mathrm{~mm} \mathrm{day}^{-1}$ over South Asia and decreases summer precipitation by $>0.6$ and $0.3-0.6 \mathrm{~mm} \mathrm{day}^{-1}$ over central and northern China, respectively. The change in winter precipitation in these regions induced by glacier expansion is negligible. A detailed analysis indicates that such changes in summer precipitation are primarily induced by glacial expansion over the Himalayas. Findings using a dry-atmospheric model show that glacial expansion over both the Pamir and Himalayan regions induces anomalous anticyclonic circulation in the middle to lower atmosphere, with the latter having a stronger influence than the former. This is probably because the Himalayas are within the region of the strongest monsoon, while the Pamir is only near the edge of the monsoonal regions. The anomalous circulation should reduce the transport of water vapor to central and northern China and increase the transport of water vapor to northern India and Pakistan.

When the same amount of glacier is added to the Tibetan Plateau in the PI climate, the changes in summer precipitation in the monsoonal regions mentioned above are much smaller than those in the LGM. Most notably, no significant weakening in summer precipitation is seen over central and northern China. This finding indicates that the detailed climate impact of glacial expansion over the Tibetan Plateau during the LGM may not be properly inferred from experiments conducted for the PI climate.

Acknowledgments. The authors are grateful to the editor and two anonymous reviewers whose advice helped improve the quality of this paper. The authors are also grateful to Peng Liu from Peking University and Jian Zhang from the Institute of Tibetan Plateau Research of China for their help in establishing the model. Y.L. benefited from discussion with Fei Liu from Nanjing University of Information Science and Technology, Bin Wang from the University of Hawaii, and Zhihong Tan from the University of Chicago. Y.L. is supported by the National Natural Science Foundation of China (Grants 41888101 and 41630527); C.Y. is supported by the Strategic Priority Research Program of the Chinese Academy of Sciences (Grant XDA20070102) and National Natural Science Foundation of China (Grant 41230523).

\section{Data availability statement:}

All data analyzed in the paper are stored on a personal server and will be available upon request from the first or corresponding authors.

\section{REFERENCES}

Anand, A., S. K. Mishra, S. Sahany, M. Bhowmick, J. S. Rawat, and S. K. Dash, 2018: Indian summer monsoon simulations: Usefulness of increasing horizontal resolution, manual tuning, and semi-automatic tuning in reducing present-day model biases. Sci. Rep., 8, 3522, https://doi.org/10.1038/S41598018-21865-1.

Annan, J. D., and J. C. Hargreaves, 2013: A new global reconstruction of temperature changes at the Last Glacial Maximum. Climate Past, 9, 367-376, https://doi.org/10.5194/cp-9-367-2013.

Arendt, A. A., and Coauthors, 2015: Randolph Glacier Inventory-A dataset of global glacier outlines: Version 5.0. GLIMS Tech. Rep., 63 pp., https://www.glims.org/RGI/00_ rgi50_TechnicalNote.pdf.

Bakke, J., and A. Nesje, 2011: Equilibrium-line altitude. Encyclopedia of Snow, Ice and Glaciers, V. P. Singh et al., Eds., Springer, $268-277$.

Boos, W. R., and Z. Kuang, 2010: Dominant control of the South Asian monsoon by orographic insulation versus plateau heating. Nature, 463, 218-222, https://doi.org/10.1038/nature08707.

and 2013: Sensitivity of the South Asian monsoon to elevated and non-elevated heating. Sci. Rep., 3, 1192, https:// doi.org/10.1038/SREP01192.

_ , and T. Storelvmo, 2016: Near-linear response of mean monsoon strength to a broad range of radiative forcings. Proc. Natl. Acad. Sci. USA, 113, 1510-1515, https://doi.org/10.1073/ pnas. 1517143113.

Duan, A. M., R. Z. Sun, and J. H. He, 2017: Impact of surface sensible heating over the Tibetan Plateau on the western Pacific subtropical high: A land-air-sea interaction perspective. $A d v$. Atmos. Sci., 34, 157-168, https://doi.org/10.1007/s00376-016-6008-z.

Gärtner-Roer, I., K. Naegeli, M. Huss, T. Knecht, H. Machguth, and M. Zemp, 2014: A database of worldwide glacier thickness observations. Global Planet. Change, 122, 330-344, https:// doi.org/10.1016/j.gloplacha.2014.09.003.

Hahn, D. G., and S. Manabe, 1975: Role of mountains in South Asian monsoon circulation. J. Atmos. Sci., 32, 1515-1541, https://doi.org/ 10.1175/1520-0469(1975)032<1515:TROMIT >2.0.CO;2.

He, F., 2011: Simulating transient climate evolution of the last deglaciation with CCSM3. Ph.D. Thesis, Center for Climatic Research, University of Wisconsin-Madison, 177 pp.

Heyman, J., 2014: Paleoglaciation of the Tibetan Plateau and surrounding mountains based on exposure ages and ELA depression estimates. Quat. Sci. Rev., 91, 30-41, https://doi.org/ 10.1016/j.quascirev.2014.03.018.

Hughes, P. D., and P. L. Gibbard, 2015: A stratigraphical basis for the Last Glacial Maximum (LGM). Quat. Int., 383, 174-185, https://doi.org/10.1016/j.quaint.2014.06.006.

Hurrell, J. W., and Coauthors, 2013: The Community Earth System Model: A framework for collaborative research. Bull. Amer. Meteor. Soc., 94, 1339-1360, https://doi.org/10.1175/BAMS-D-12-00121.1.

Huybrechts, P., and S. T'Siobbel, 1995: Thermomechanical modelling of Northern Hemisphere ice sheets with a two-level mass-balance parameterization. Ann. Glaciol., 21, 111-116, https://doi.org/10.1017/S0260305500015688.

Jiang, D., H. Wang, and X. Lang, 2002: Possible influence of the Tibetan ice sheet on the climate of Last Glacial Maximum (in Chinese). Quat. Sci., 22, 323-331.

_ - - H. Drange, and X. M. Lang, 2003: Last Glacial Maximum over China: Sensitivities of climate to paleovegetation and Tibetan ice sheet. J. Geophys. Res., 108, 4102, https://doi.org/ 10.1029/2002JD002167. 
_- Z. Tian, and X. Lang, 2016: Reliability of climate models for China through the IPCC Third to Fifth Assessment Reports. Int. J. Climatol., 36, 1114-1133, https://doi.org/ 10.1002/joc.4406.

— Y. Yiu, and X. Lang, 2019: A multi-model analysis of glacier equilibrium line altitudes in western China during the Last Glacial Maximum. Sci. China Earth Sci., 62, 1241-1255, https://doi.org/10.1007/s11430-018-9266-8.

Jin, L., A. Ganopolski, F. Chen, M. Claussen, and H. Wang, 2005: Impacts of snow and glaciers over Tibetan Plateau on Holocene climate change: Sensitivity experiments with a coupled model of intermediate complexity. Geophys. Res. Lett., 32, L17709, https://doi.org/10.1029/2005GL023202.

— H. J. Vang, F. H. Chen, and D. B. Jiang, 2006: A possible impact of cooling over the Tibetan Plateau on the midHolocene East Asian monsoon climate. Adv. Atmos. Sci., 23, 543-550, https://doi.org/10.1007/s00376-006-0543-y.

-, Y. Peng, F. Chen, and A. Ganopolski, 2009: Modeling sensitivity study of the possible impact of snow and glaciers developing over Tibetan Plateau on Holocene African-Asian summer monsoon climate. Climate Past, 5, 457-469, https:// doi.org/10.5194/cp-5-457-2009.

Kirchner, N., R. Greve, J. Heyman, and A. Stroeven, 2009: Tibetan Plateau glaciation during the last glacial cycle: Widely diverging (LGM-) reconstructions of glacial extents using numerical ice sheet simulations driven by GCM-ensembles of climate forcings. Geophysical Research Abstracts, Vol. 11, Abstract 1791, https://meetingorganizer.copernicus.org/EGU2009/ EGU2009-1791.pdf.

_ — _ A. P. Stroeven, and J. Heyman, 2011: Paleoglaciological reconstructions for the Tibetan Plateau during the last glacial cycle: Evaluating numerical ice sheet simulations driven by GCM-ensembles. Quat. Sci. Rev., 30, 248-267, https://doi.org/ 10.1016/j.quascirev.2010.11.006.

Kuhle, M., 1985: Glaciation research in the Himalayas: A new ice age theory. Universitas, 27, 281-294.

, 1998: Reconstruction of the 2.4 million $\mathrm{km}^{2}$ late Pleistocene ice sheet on the Tibetan Plateau and its impact on the global climate. Quat. Int., 45-46, 71-108, https://doi.org/10.1016/ S1040-6182(97)00008-6.

- 2005: Glacial geomorphology and ice ages in Tibet and the surrounding mountains. Isl. Arc, 14, 346-367, https://doi.org/ 10.1111/j.1440-1738.2005.00501.x.

Lee, J.-Y., and B. Wang, 2014: Future change of global monsoon in the CMIP5. Climate Dyn., 42, 101-119, https://doi.org/10.1007/ s00382-012-1564-0.

Li, B., and J. Li, 1991: Map of Quaternary trace of glaciers over the Tibetan Plateau (in Chinese). Science Press, 1 p.

Li, C. F., and M. Yanai, 1996: The onset and interannual variability of the Asian summer monsoon in relation to land-sea thermal contrast. J. Climate, 9, 358-375, https://doi.org/10.1175/15200442(1996)009<0358:TOAIVO>2.0.CO;2.

Lin, H., and Z. W. Wu, 2011: Contribution of the autumn Tibetan Plateau snow cover to seasonal prediction of North American winter temperature. J. Climate, 24, 2801-2813, https://doi.org/ 10.1175/2010JCLI3889.1.

$\longrightarrow$, and - 2012: Contribution of Tibetan Plateau snow cover to the extreme winter conditions of 2009/10. Atmos.-Ocean, 50, 86-94, https://doi.org/10.1080/07055900.2011.649036.

Lin, Z., F. Liu, B. Wang, R. Lu, and X. Qu, 2017: Southern European rainfall reshapes the early-summer circumglobal teleconnection after the late 1970s. Climate Dyn., 48, 38553868, https://doi.org/10.1007/s00382-016-3306-1.
Liu, G., R. G. Wu, Y. Z. Zhang, and S. L. Nan, 2014: The summer snow cover anomaly over the Tibetan Plateau and its association with simultaneous precipitation over the mei-yu-baiu region. Adv. Atmos. Sci., 31, 755-764, https://doi.org/10.1007/ s00376-013-3183-Z.

Liu, S. Z., Q. G. Wu, X. J. Ren, Y. H. Yao, S. R. Schroeder, and H. Hu, 2017: Modeled Northern Hemisphere autumn and winter climate responses to realistic Tibetan Plateau and Mongolia snow anomalies. J. Climate, 30, 9435-9454, https://doi.org/10.1175/ JCLI-D-17-0117.1.

Liu, X. D., and Z. Y. Yin, 2002: Sensitivity of East Asian monsoon climate to the uplift of the Tibetan Plateau. Palaeogeogr., Palaeoclimatol., Palaeoecol., 183, 223-245, https://doi.org/ 10.1016/S0031-0182(01)00488-6.

Liu, Y. M., Z. Q. Wang, H. F. Zhuo, and G. X. Wu, 2017: Two types of summertime heating over Asian large-scale orography and excitation of potential-vorticity forcing II. Sensible heating over Tibetan-Iranian Plateau. Sci. China Earth Sci., 60, 733744, https://doi.org/10.1007/s11430-016-9016-3.

Lu, M., S. Yang, Z. Li, B. He, S. He, and Z. Wang, 2018: Possible effect of the Tibetan Plateau on the "upstream" climate over west Asia, North Africa, south Europe and the North Atlantic. Climate Dyn., 51, 1485-1498, https://doi.org/10.1007/s00382017-3966-5.

Ma, D., W. Boos, and Z. M. Kuang, 2014: Effects of orography and surface heat fluxes on the South Asian summer monsoon. J. Climate, 27, 6647-6659, https://doi.org/10.1175/JCLI-D-1400138.1

Nuimura, T., and Coauthors, 2015: The GAMDAM glacier inventory: A quality-controlled inventory of Asian glaciers. Cryosphere, 9, 849-864, https://doi.org/10.5194/tc-9-849-2015.

Owen, L. A., and J. M. Dortch, 2014: Nature and timing of Quaternary glaciation in the Himalayan-Tibetan orogen. Quat. Sci. Rev., 88 , 14-54, https://doi.org/10.1016/j.quascirev.2013.11.016.

Sampe, T., and S. P. Xie, 2010: Large-scale dynamics of the meiyubaiu rainband: Environmental forcing by the westerly jet. J. Climate, 23, 113-134, https://doi.org/10.1175/2009JCLI3128.1.

Schmidt, G. A., and Coauthors, 2012: Climate forcing reconstructions for use in PMIP simulations of the Last Millennium (v1.1). Geosci. Model Dev., 5, 185-191, https://doi.org/10.5194/ gmd-5-185-2012.

Shi, Y., B. Zheng, and S. Li, 1992: Last glaciation and maximum glaciation in the Qinghai-Xizang (Tibet) Plateau: A controversy to M. Kuhle's ice sheet hypothesis. Chin. Geogr. Sci., 2 293-311, https://doi.org/10.1007/BF02664561.

,--1, and T. Yao, 1997: Glaciers and environments during the Last Glacial Maximum (LGM) on the Tibetan Plateau (in Chinese). J. Glaciol. Geocryol., 19, 97-113.

Snyder, C. W., 2016: Evolution of global temperature over the past two million years. Nature, 538, 226-228, https://doi.org/ 10.1038/nature19798.

Son, J. H., K. H. Seo, and B. Wang, 2019: Dynamical control of the Tibetan Plateau on the East Asian summer monsoon. Geophys. Res. Lett., 46, 7672-7679, https://doi.org/10.1029/ 2019 GL083104.

Sperber, K. R., H. Annamalai, I.-S. Kang, A. Kitoh, A. Moise, A. Turner, B. Wang, and T. Zhou, 2013: The Asian summer monsoon: An intercomparison of CMIP5 vs. CMIP3 simulations of the late 20th century. Climate Dyn., 41, 2711-2744, https://doi.org/10.1007/s00382-012-1607-6.

Tarasov, L., and W. R. Peltier, 1997: Terminating the $100 \mathrm{kyr}$ ice age cycle. J. Geophys. Res., 102, 21 665-21 693, https://doi.org/ 10.1029/97JD01766. 
and - 1999: Impact of thermomechanical ice sheet coupling on a model of the $100 \mathrm{kyr}$ ice age cycle. J. Geophys. Res., 104, 9517-9545, https://doi.org/10.1029/1998JD200120.

Vinoj, V., P. J. Rasch, H. L. Wang, J. H. Yoon, P. L. Ma, K. Landu, and B. Singh, 2014: Short-term modulation of Indian summer monsoon rainfall by west Asian dust. Nat. Geosci., 7, 308-313, https://doi.org/10.1038/ngeo2107.

Wang, B., and Q. H. Ding, 2008: Global monsoon: Dominant mode of annual variation in the tropics. Dyn. Atmos. Oceans, 44, 165-183, https://doi.org/10.1016/j.dynatmoce.2007.05.002.

Wang, P. X., B. Wang, H. Cheng, J. Fasullo, Z. T. Guo, T. Kiefer, and Z. Y. Liu, 2017: The global monsoon across time scales: Mechanisms and outstanding issues. Earth-Sci. Rev., 174, 84121, https://doi.org/10.1016/j.earscirev.2017.07.006.

Watanabe, M., and M. Kimoto, 2000: Atmosphere-ocean thermal coupling in the North Atlantic: A positive feedback. Quart. J. Roy. Meteor. Soc., 126, 3343-3369, https://doi.org/10.1002/ qj.49712657017; Corrigendum, 127, 733-734, https://doi.org/ 10.1002/qj.49712757223.

Wu, G. X., and Coauthors, 2007: The influence of mechanical and thermal forcing by the Tibetan Plateau on Asian climate. J. Hydrometeor., 8, 770-789, https://doi.org/10.1175/JHM609.1.

_, and Coauthors, 2015: Tibetan Plateau climate dynamics: Recent research progress and outlook. Natl. Sci. Rev., 2, 100 116, https://doi.org/10.1093/nsr/nwu045.

- H. F. Zhuo, Z. Q. Wang, and Y. M. Liu, 2016: Two types of summertime heating over the Asian large-scale orography and excitation of potential-vorticity forcing I. Over Tibetan Plateau. Sci. China Earth Sci., 59, 1996-2008, https://doi.org/ 10.1007/s11430-016-5328-2.

Wu, Y., Y. Liu, C. Yi, and P. Liu, 2019: Impact of Tibetan glacier change on the Asian climate during the Last Glacial Maximum (in Chinese). Beijing Daxue Xuebo Ziran Kexuebao, 55, 159-170.
Xu, X. K., and N. F. Glasser, 2015: Glacier sensitivity to equilibrium line altitude and reconstruction for the Last Glacial cycle: Glacier modeling in the Payuwang Valley, western Nyaicientanggulha Shan, Tibetan Plateau. Palaeogeogr. Palaeoclimatol. Palaeoecol., 440, 614-620, https://doi.org/10.1016/ j.palaeo.2015.09.025.

— , and C. L. Yi, 2017: Timing and configuration of the Gongga II glaciation in the Hailuogou valley, eastern Tibetan Plateau: A glacier-climate modeling method. Quat. Int., 444, 151-156, https://doi.org/10.1016/j.quaint.2017.01.011.

—, B. L. Pan, G. C. Dong, C. L. Yi, and N. F. Glasser, 2017: Last Glacial climate reconstruction by exploring glacier sensitivity to climate on the southeastern slope of the western Nyaiqentanglha Shan, Tibetan Plateau. J Glaciol., 63, 361-371, https://doi.org/ 10.1017/jog.2016.147.

Yan, M., B. Wang, and J. Liu, 2016: Global monsoon change during the Last Glacial Maximum: A multi-model study. Climate Dyn., 47, 359-374, https://doi.org/10.1007/s00382015-2841-5.

Yan, Q., L. A. Owen, H. J. Wang, and Z. S. Zhang, 2018: Climate constraints on glaciation over high-mountain Asia during the Last Glacial Maximum. Geophys. Res. Lett., 45, 9024-9033, https://doi.org/10.1029/2018GL079168.

Yasui, S., and M. Watanabe, 2010: Forcing processes of the summertime circumglobal teleconnection pattern in a dry AGCM. J. Climate, 23, 2093-2114, https://doi.org/10.1175/ 2009JCLI3323.1.

Ye, D. Z., and G. X. Wu, 1998: The role of the heat source of the Tibetan Plateau in the general circulation. Meteor. Atmos. Phys., 67, 181-198, https://doi.org/10.1007/BF01277509.

Zhu, J., and Coauthors, 2017: Reduced ENSO variability at the LGM revealed by an isotope-enabled Earth system model. Geophys. Res. Lett., 44, 6984-6992, https://doi.org/10.1002/ 2017GL073406. 